\title{
Cross-Layer Energy Optimization for IoT Environments: Technical Advances and Opportunities
}

\author{
Kirshna Kumar $^{1}$, Sushil Kumar ${ }^{1}$, Omprakash Kaiwartya ${ }^{2}$ (D), Yue Cao ${ }^{2, *}$ (D) $^{\text {, Jaime }}$ Lloret $^{3}$ \\ and Nauman Aslam ${ }^{2}$ \\ 1 School of Computer \& Systems Sciences, Jawaharlal Nehru University, New Delhi 110067, India; \\ kirshn44_scs@jnu.ac.in (K.K.); skdohare@mail.jnu.ac.in (S.K.) \\ 2 Department of Computer and Information Sciences, Northumbria University, Newcastle NE2 1XE, UK; \\ omprakash.kaiwartya@northumbria.ac.uk (O.K.); nauman.aslam@northumbria.ac.uk (N.A.) \\ 3 Department of Communications, Polytechnic University of Valencia, Camino de Vera, 46022 Valencia, Spain; \\ jlloret@dcom.upv.es \\ * Correspondence: yue.cao@northumbria.ac.uk; Tel.: +44-7709694048
}

Received: 27 October 2017; Accepted: 28 November 2017; Published: 6 December 2017

\begin{abstract}
Energy efficiency is a significant characteristic of battery-run devices such as sensors, RFID and mobile phones. In the present scenario, this is the most prominent requirement that must be served while introducing a communication protocol for an IoT environment. IoT network success and performance enhancement depend heavily on optimization of energy consumption that enhance the lifetime of IoT nodes and the network. In this context, this paper presents a comprehensive review on energy efficiency techniques used in IoT environments. The techniques proposed by researchers have been categorized based on five different layers of the energy architecture of IoT. These five layers are named as sensing, local processing and storage, network/communication, cloud processing and storage, and application. Specifically, the significance of energy efficiency in IoT environments is highlighted. A taxonomy is presented for the classification of related literature on energy efficient techniques in IoT environments. Following the taxonomy, a critical review of literature is performed focusing on major functional models, strengths and weaknesses. Open research challenges related to energy efficiency in IoT are identified as future research directions in the area. The survey should benefit IoT industry practitioners and researchers, in terms of augmenting the understanding of energy efficiency and its IoT-related trends and issues.
\end{abstract}

Keywords: Internet of Things; energy efficiency; smart technologies; green computing; heterogeneous networks

\section{Introduction}

The Internet of Things (IoT) is revolutionizing and extending existing fundamental research areas into new dimensions by integrating the concept of intelligence or smartness [1,2]. The new domains, including intelligent transportation systems, smart cities, smart homes, smart industries, autonomous vehicle, smart healthcare are but a few examples of this revolution [3,4]. Some other prominent IoT application domains include automated security devices such as alarms and surveillance systems, automated grids used in industrial metering, vehicular telematics as support for navigation and fleet management, remote maintenance as in vending machine control and industrial automation, and manufacturing control as in production chain monitoring $[5,6]$. The integration of IoT in almost every aspect of human lives is due to the focus of inventions towards a greener and smarter world for sustainability reasons [7]. IoT use case implementations are increasing day by day. In 2003, 500 million devices were connected to Internet, while the population of the world was 6.3 billion. It is predicted that the number of connected devices will be approximately 50 billion by 2022 , which is equivalent to 
four times the world's population. This estimated steep growth shows both the exponential expansion rate of IoT in the world and our dependence on IoT enabled devices $[8,9]$.

Towards realizing a smarter world via IoT enabled connected devices, there are two major constraints for tiny and smarter devices, namely, communication and computing power constraints due to the limitation of energy resources. The main power supply resource in most sensor-enabled IoT devices is a battery, whereby operating sensors consume battery power for collection and transmission of data among neighborhood devices. The accuracy of sensed and collected information is enhanced via analysis of the data. However, the analysis increases the energy consumption in IoT devices [10]. The sensor-enabled smart devices operate, i.e., they sense, receive, compute and disseminate information continuously, to facilitate automating intelligent decisions. The optimization of energy consumption in sensor-enabled IoT devices has become one of the fundamental issues due to the integration of sustainability in recent greener, and smarter world research [11]. Technical standardization bodies such as the Institute of Electrical and Electronics Engineering (IEEE), 3rd Generation Partnership Projects (3GPP) and the European Telecommunications Standard Institute (ETSI) have introduced various energy efficient approaches for sensor-enabled IoT devices [12]. In the related literature, various techniques have been suggested for optimizing energy consumption in sensor-enabled IoT devices. The techniques span focusing different aspects of IoT communication and computation for optimizing energy consumption in specific use cases. This energy-oriented diverse IoT domain can be systematically explored using a five-layered architecture (see Figure 1). The cross layer optimizations have been proven better in the literature due to the consideration of diverse aspects of communication and computing for scalable IoT use case implementation environments. Figure 1 shows a communication architecture of different IoT use case implementations focusing on the energy consumption aspects. It consists of five layers including sensing layer (SL), local processing and storage layer (LPSL), network/communication layer (NCL), cloud processing and storage layer (CPSL) and application layer (AL). The layer wise issues have been also highlighted.

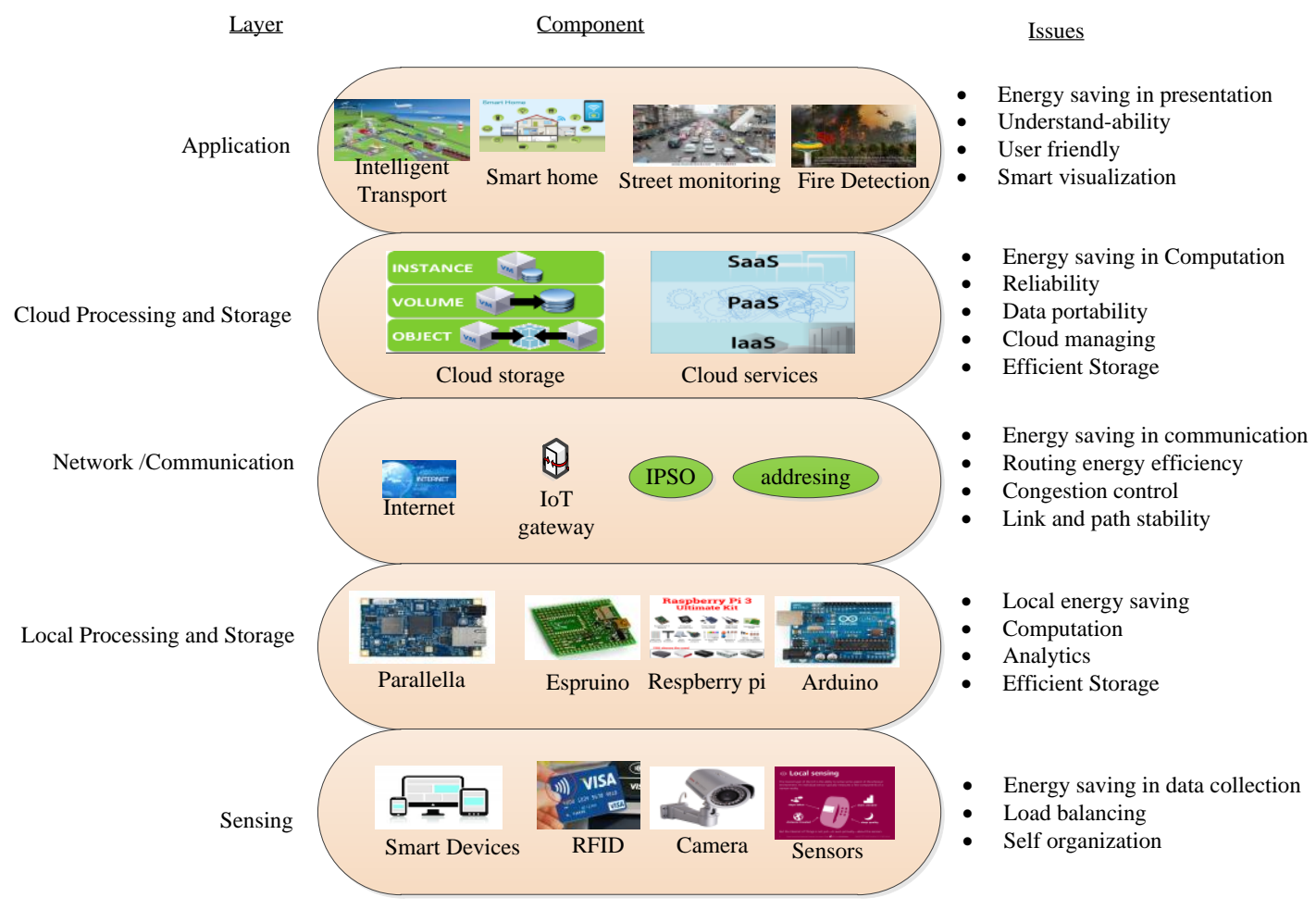

Figure 1. Energy consumption-oriented layered architecture for IoT. 
This paper presents a comprehensive survey on energy optimization in IoT environments focusing on layerwise studies in the area. The energy-oriented techniques have been categorically criticized in terms of their technical contributions and limitations considering different energy-related metrics. Specifically, the contributions of this paper can be divided into following three aspects:

- Firstly, the significance of cross-layer energy optimization in IoT environments is highlighted focusing on different use case implementations.

- Secondly, following the layered taxonomy, a model-based qualitative review is carried out on energy optimization in IoT environments focusing on major functional components, strengths and weaknesses.

- Finally, open research issues and challenges in energy optimization for IoT are identified as future research and development directions in the area.

The remaining sections of the paper are structured as follows: in Section 2, the significance of cross-layer energy optimization in IoT environments is highlighted. In Section 3, related literature surveys on IoT have been revisited. Section 4 presents a comprehensive review on energy optimization in IoT focusing on layered taxonomy, model-based discussion and comparative analysis of recent developments. In Section 5, open research issues and challenges for energy efficiency under IoT environments are identified, followed by conclusions presented in Section 6.

\section{Significance of Energy Efficiency in IoT Use Cases}

In this section, a description about the significance of cross-layer energy optimization in IoT environments is presented, while focusing on various use case implementations.

\subsection{Case Study: Smart Home}

IoT is a technological phenomenon that connects the physical and the computing worlds, while enabling ubiquitous communication at any time using various services for smart home applications. For domestic purposes such as heating control, security, lighting, etc., the smart home concept provides efficient management mechanisms, with increasing usage of smart devices. The smart home control system based on Coordinator-based ZigBee networking (CoZNET) mitigates the interference effect and minimizes the energy consumption of domestic appliances [13]. Moreover the workings of a smart home system based on CoZNET is divided into three sections, namely Smart Interference Control System (SICS), Smart Energy Control System (SECS) and Smart Management Control System (SMCS). SICS enables the smoother communication with lesser packet loss, while mitigating interference effects using multi-attribute decision making-based channel assignment mechanism in the entire smart home. SECS further reduces energy consumption in the smart home, with the usage of a light control system and a household appliance control system, then a number of facilities are provided to users for exploiting the control of the entire smart home system, while implementing a fundamental unit called SMCS.

Figure 2 shows the smart home scenario including various domestic appliances such as an air conditioner, refrigerator, dishwasher, washing machine, lights, television, etc. Among these appliances, some appliances consume more electricity, namely the refrigerator, air conditioner, etc. and some consume less electricity such as the lights, television, etc. Moreover electricity consumption for a single appliance also varies based on the execution cycle phase considered. For example, in a washing machine, the electricity consumption of a drying cycle is more than the electricity consumption of a washing cycle. Therefore it is challenging to manage the usage of these domestic appliances in a smart home system efficiently, while minimizing the electricity consumption. Therefore, the issue of energy efficiency plays a significant role to make a smart home system efficient. 


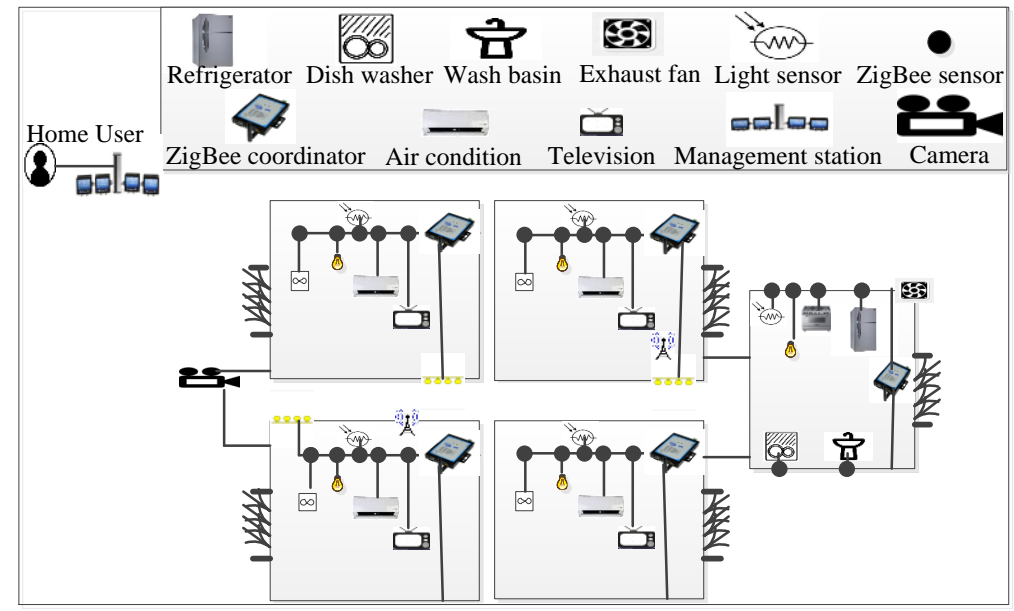

Figure 2. Smart home control system.

\subsection{Case Study: Smart Car}

Looking beyond prevalence as in the evolution of mobile phones into smartphones, dumb TVs to smart TVs, the IoT has evolved the traditional car into smart cars, while including the properties of ubiquitous computing, human computer interaction and application platforms for smart cars. Therefore, a novel smart car demonstration platform has been presented, in which a transparent windshield display and a number of sensors have been equipped for receiving and displaying virtual information to the driver [14]. Additionally while considering urban street driving scenarios, three potential applications namely, a visibility restoration application, a driving environment understanding application and a nighttime contrast enhancement application have been discussed to provide operational safety to smart cars.

Figure 3 illustrates the system architecture of the smart car demonstration platform, focusing on its three major units namely, the interaction unit, computing and communication unit, and application unit. Through the application unit, an open platform is provided to the smart car for users to download applications from government/private utility providers or automobile companies in order to customize the vehicle's performance, features and capabilities. In order to meet the requirements of the users in areas such as entertainment, communication and social, shopping, travel utilities, smart car-appropriate applications can be developed. In a smart car system, because of the usage of various battery powered devices such as sensors, display units, computing and communication devices, the energy consumption in terms of fuel, electricity, etc. can be increased. Therefore minimizing the energy consumption in smart car-enabled IoT applications will be a significant issue in the future.

\begin{tabular}{|c|c|}
\hline \multicolumn{2}{|c|}{ Application Unit } \\
\hline Automobile Companies & Government Utility Provider \\
\hline Insurance Companies & Private Utility Provider \\
\hline \multicolumn{2}{|c|}{ Computing and Communication Unit } \\
\hline \multirow{2}{*}{$\begin{array}{c}\text { Communication mgmt } \\
\text { Bluetooth, Wi-Fi, NFC, } \\
\text { 3G/3.5G/4G/LTE }\end{array}$} & Device Management \\
\hline & Operating System \\
\hline \multicolumn{2}{|c|}{ Interaction Unit } \\
\hline \multirow{4}{*}{$\begin{array}{c}\text { Transparent Windshield } \\
\text { Display }\end{array}$} & Eye Sensors \\
\hline & Image Sensors \\
\hline & Voice Sensors \\
\hline & Gesture Sensors \\
\hline
\end{tabular}

Figure 3. System architecture of a Smart Car demonstration platform. 


\subsection{Case Study: Smart Logistics}

Traditional transport logistics systems are not efficient because of a lack of coordination and sharing among the entities transported by logistic vendors, for e.g., trucks returning empty and partially full trucks. This results wastage of goods, resources, etc. Therefore, a novel concept of Internet of Perishable Logistics (IoPL) has been introduced to make transportation more intelligent and efficient, in which transportation of package or packages containers between a source (for e.g., a factory, a farm, etc.) and destination (for e.g., a retailer) is similar to the flow of packets in the Internet [15]. Hence a layered architecture for IoPL has been proposed, while borrowing from cyber Internet with various issues identified in the logistics system. The key issues identified in IoPL are standardization (loading, unloading and storing machines and their internet enablement using IoT devices), resource and infrastructure sharing. The enablement of information and communication technology (ICT)-based capabilities (RFID-based labeling/addressing, barcoding, GPS-based localization, IoT-based sensing and actuation, etc.) will make a smart logistic system more proactive and efficient.

In Figure 4 quality sensing and communication of product boxes is illustrated, which is one of the aspects of minimizing wastage of food because of spoilage and contamination. Tiny sensors such as Food Scan, C2Sense, etc. are inserted into containers or shipping boxes at the time of delivery inside a warehouse or in a truck. Then these sensed data along with a box ID for food contamination tracking are transmitted to the central controller through an appropriate sensor network. During the flow of data in the Internet, energy consumption is focus issue for localization, scheduling, communication, etc. In a similar way, during the flow of package containers from source to destination the issue of energy consumption is a major challenge before the researchers for sensing, standardization, resource sharing, transportation, etc. to provide an efficient smart logistics system in IoPL.

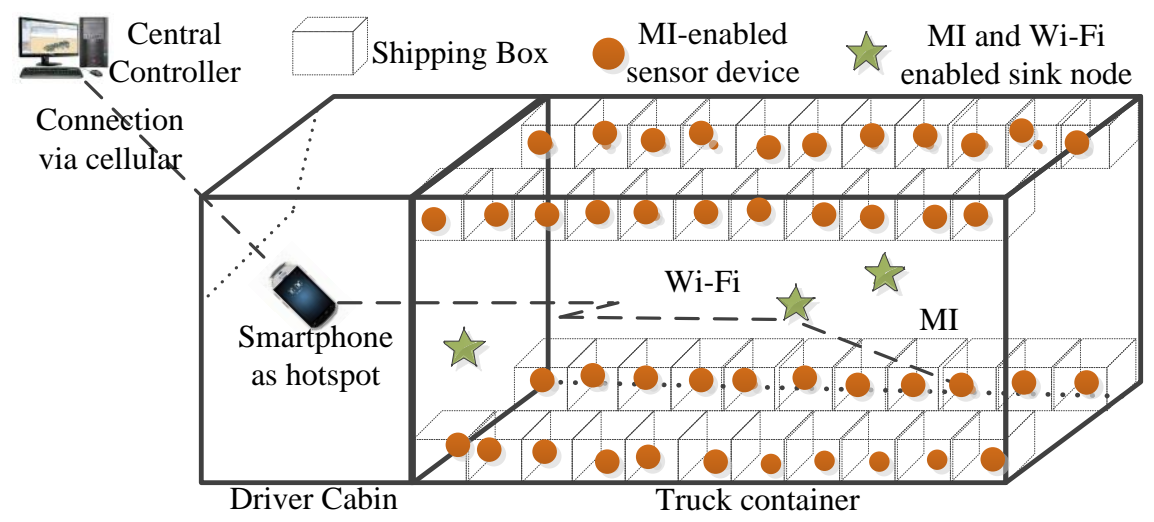

Figure 4. Quality sensing and communication for product boxes.

\subsection{Case Study: Smart Agriculture}

Water and electricity both are the most prominent input parameters in agricultural systems. In a situation of inadequate rainfall, crop production is restricted due to inefficient usage of water resources and irrigation scheduling. From this perspective, the Cloud of Things (CoT)-based smart irrigation system has been introduced to utilize water and energy in an effective and efficient way, while enhancing agricultural production [16]. The irrigation system becomes more efficient and less costly by smart water usage (supervising and monitoring water capacity, timing, location and duration of flow on the basis of data analytics). The combination of data analytics collection from the CoT (weather situation, type of soil, land condition, crop features, etc.) and data capture by sensors measuring moisture, heat, water stress, chemicals, etc., provide practical information. This information helps farmers utilize fertilizers, water and pesticides in appropriate locations and quantities.

Figure 5 illustrates a real time CoT-based smart irrigation system, by enabling task automation based on the data received by the sensors and the devices. In addition, performance statistics and 
reports are generated, while providing real time information to the farmer based on the business activity, which helps the farmer to make timely and well-informed decisions. Then the farmer can benefit in terms of data access, storage, synchronization and cost, when farming applications are moved to the cloud daily. In the applications related to smart agriculture, energy usage is also one of the most crucial parameters in terms of lighting, boosters, pumps and other purposes. In the future, energy-efficient smart agricultural system should be proposed, while considering other parameters such as water based on IoT capabilities.

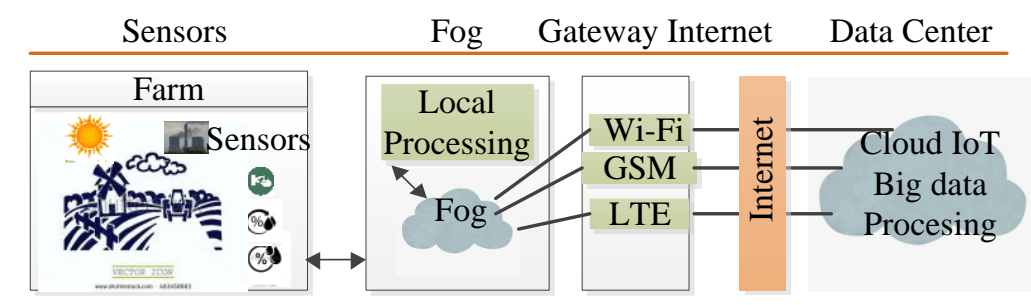

Figure 5. Real time CoT-based automated irrigation system.

\subsection{Case Study: Smart Fabric}

During the 1990-2000 period the smart clothes concept merging ICT capabilities (sensing, actuating, computing and communication) with clothes and textiles to augment their appeal and develop protective textiles was explored by several companies (Philips, Infineon, DuPont, etc.). Multimodal sensor, human-computer interface, continuous Internet access, long distance communication and unobtrusive packaging functionalities are available in smart phone apps for smart textile systems. In applications such as sports, healthcare, protection and maintenance, a larger area and closer contact with skin than possible with sensors or smartphones is required. Textile electrodes provide better, continuous and direct skin contact for recording skin conductance for stress evaluation, measuring ECG or estimating local pressure to prevent ulcers [17]. Several smart textile technologies to scale up weaving of integrated circuits into textiles have been proposed. Strain, humidity, and temperature sensing, light transport and fluid monitoring functionalities have been enabled in threads. Because of the smaller surface and limited functional complexity achievable in a textile thread, several wearable threads equipped with sensors and transceiver-integrated CMOS circuits provide higher functional density, but smart cloth is still a very new research area in IoT even before researchers consider various issues such as efficient energy usage, reliability, less cost, etc. Because of the smart devices such as sensors, smartphone, CMOS circuits used in smart clothes systems, energy consumption has become the crucial issue for the future.

\subsection{Simulation Oriented Characterization}

In this section, recent technical developments in energy-oriented architectures and protocols for IoT environments are explored experimentally in a realistic simulation environment. The comparative investigation focuses on the performance monitoring of state-of-the-art techniques considering energy-oriented network evaluation metrics. The simulations have been performed on a NS2 network simulator considering a $100 \mathrm{~m} \times 100 \mathrm{~m}$ square experimental area with 500 nodes for a total simulation duration of $60 \mathrm{~min}$ to represent an IoT-based monitoring scenario. For robust experimental verification a standard simulator has been used considering its usage in a wide range of experiments. The major simulation parameters listed in Table 1 are used to conduct 25 rounds of repeated experiments considering different arbitrary seed numbers to acquire a 95\% certainty interval. In this section, various routing protocols, namely AODV, ER-RPL, REL and FFSC, are simulated and analyzed using the mentioned simulation parameters. The focus of this simulation-based evaluation is to realize a resource-constrained scenario in an IoT environment. To this end, lower transmission range limit, lower power consumption rate in signal transmission and reception, a restricted area for 
monitoring are the major considered parameter settings. As initial results, two metrics are considered for evaluating some data dissemination techniques under an IoT centric parameter settings in the simulation environment, namely packet delivery ratio and network lifetime. The precise definition of network lifetime in sensor-enabled networks depends on the application scenario. For example, security-oriented monitoring applications require continuous operation of each node in the network, i.e., energy exhaustion of even $1 \%$ of the nodes is considered the network lifetime limit, whereas in normal environmental monitoring applications, energy exhaustion of even $10 \%$ of the nodes is not considered the network lifetime limit assuming that $90 \%$ of the network nodes can still perform their tasks smoothly. In our simulation-based network evaluation case, the energy exhaustion of $2 \%$ of the nodes is considered the network lifetime considering the connectivity-oriented IoT environment target application scenario.

Table 1. Simulation parameters.

\begin{tabular}{cc}
\hline Parameters & Values \\
\hline Simulation area & $100 \mathrm{~m} \times 100 \mathrm{~m}$ \\
\hline Simulation time & $70 \mathrm{~m}$ \\
\hline Number of Nodes & 500 \\
Topology & random \\
\hline Initial Energy & $0511 \mathrm{~W}$ \\
Power for transmission & $0588 \mathrm{~W}$ \\
Power for reception & $(60,60)$ \\
\hline Base station Location & $0.2 \mathrm{~m}$ \\
\hline Transmission range & 5 \\
Transmission limit & Source and destination specific \\
The radius of network & $3 \mathrm{p} / \mathrm{s}$ \\
The traffic rate &
\end{tabular}

Considering a $2 \%$ dead nodes situation as a monitoring threshold, Figure 6 a shows the network lifetime of various protocols (AODV, ER-RPL, REL and FFSC) under various node densities According to Figure $6 \mathrm{a}$, network lifetime is defined as the number of rounds until $2 \%$ of the nodes die. In all simulation scenarios with 100, 200 and 500 nodes, FFSC outperforms other protocols, in terms of lifetime, then ER-RPL and REL have equal lifetimes, and AODV performs the worst. Figure $6 \mathrm{~b}$ shows the percentage of alive nodes as the simulation time increases. Two measurement metrics were used to assess the energy efficiency: network lifetime and the saturation time of the IoT network.

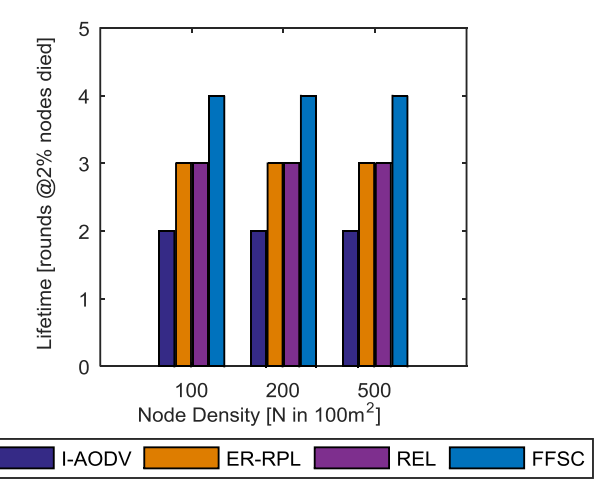

(a)

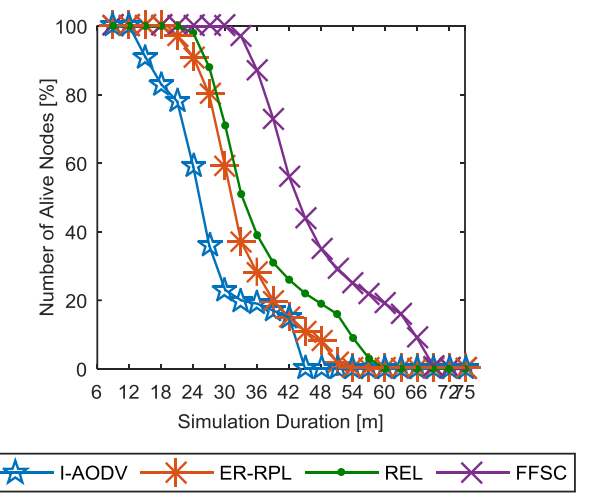

(b)

Figure 6. Cont. 


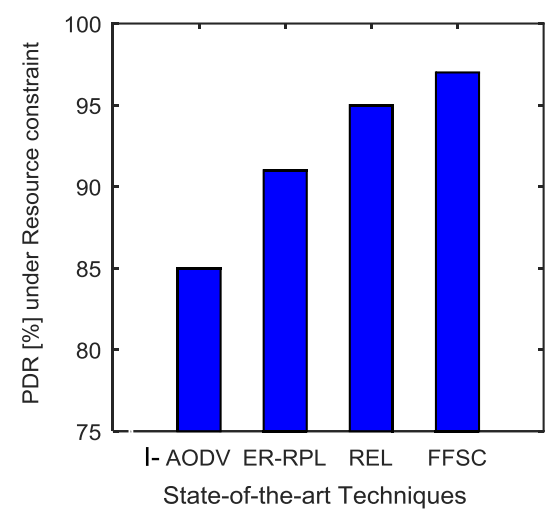

(c)

Figure 6. Simulation based evaluation results: (a) network lifetime in number of communication rounds; (b) percentage of nodes alive during the entire simulation time; (c) packet delivery ratio in resource constrained environments.

According to Figure $6 \mathrm{~b}$, the network lifetime is defined as the time spent by device nodes in the IoT network until the moment when only $1 \%$ of the nodes remain alive. The saturation time is like the network lifetime, except its measurement begins from the point when the first node dies. Saturation time values allow one to evaluate the ability of a routing algorithm to effectively adjust to another topology due to the death of nodes. In a 100 node density case, the saturation time of AODV is 33 min, which is less than the saturation time of FFSC (39 min), while ER-RPL and REL lay between AODV and FFSC. The network lifetime of FFSC is $69 \mathrm{~min}$, which is 9, 15 and $24 \mathrm{~min}$ more than REL, ER-RPL and AODV, respectively. Therefore, in terms of network lifetime and saturation time, FFSC is the most suitable protocol, followed by REL, then ER-RPL, and AODV is the least suitable. The reliability of the existing routing protocols AODV, ER-RPL, REL and FFSC has been measured using packet delivery ratio (PDR) which is described as the ratio of the number of successfully transmitted packets to the total number of transmitted packets. Figure $6 c$ illustrates the PDR in the simulated scenario with 100 nodes for all packet transmissions, while establishing an interval from $75 \%$ to $100 \%$. As can be seen in Figure 6c, FFSC, which delivers 97\% packets successfully outperforms AODV (85\%), ER-RPL (91\%) and REL (95\%), respectively and AODV delivers the least packets successfully.

\section{Related Literature Reviews}

Due to the unavailability of extensive surveys on energy efficiency in the IoT, in this section reviews on the IoT are revisited, focusing on vehicular ad-hoc networks, wireless sensor networks and various other areas. A survey on different protocols, technologies and applications related to the IoT has been performed [18]. In [19] a comprehensive overview related to IoT is presented, focusing on system architecture, enabled technologies, privacy and security issues, applications and integration between edge/fog computing and the IoT. From the perspective of context-aware technology, product development and research, an examination of a variety of innovative and popular IoT solutions was done [20]. A survey of prominent research related to the combined area of mobile phone computing and Internet of Things/Web of Things was provided in [21]. A review on technologies utilized in data routing and a framework of structural health monitoring for reliable and intelligent monitoring has been presented in [22]. A review on existing middleware solutions for radio frequency identification, machine to machine communication, supervisory control and data acquisition in the IoT has been presented in [23]. Various applications related to economic analysis and pricing models, while developing adaptive protocols for data storage and wireless communication in IoT environment, have been reviewed [24]. A survey about context awareness in IoT, while addressing various techniques, models, methods, functionalities, middleware solutions and applications related to it is presented 
in [25]. The architectures and frameworks of cognitive radio-based IoT systems are surveyed in [26], while highlighting open issues, research challenges and applications related to it. The research efforts in IoT-based smart environments have been surveyed on the basis of network types, local area wireless standards, technologies and human life [27]. The framework of the Internet of Vehicles is presented in [3], while emphasizing motivation, five layered architecture with functionalities of each layer, network model, challenges and future aspects inside the IoT. It presents a network model based on three elements: client, connection and cloud. A survey on machine to machine systems, while introducing their architecture and communication networks and categorizing them based on the types of machine to machine context, task and objective has been performed [28]. Recent solutions for machine to machine systems have been also surveyed. To support machine to machine communications in the IoT environment, existing Medium Access Control (MAC) layer protocols have been surveyed, while including technical challenges, requirements and existing work related to them [29]. A survey based on integration of the cloud with IoT was performed, considering challenges, research issues and applications related to their integration [30]. In order to provide integration between smart homes and cloud-centric IoT efficiently, a framework based on various components of the IoT is proposed [31]. A smart home management model has been identified for this framework with its challenges.

\section{Energy Efficient Techniques in the IoT}

In this section, energy efficiency techniques in the IoT are qualitatively reviewed based on the taxonomy shown in Figure 7. The proposed techniques have been categorized based on five different layers of the IoT energy architecture. These five layers are named SL, LPSL, NCL, CPS and AL. The existing techniques at the sensing layer, are further classified in three categories: energy efficient sleep/wakeup, modulation and SoT-based techniques. Energy harvesting and cognitive ratio-based techniques are two more categorizations at the LPSL layer. The existing techniques at the NCL layer are also categorized in three categories, named as energy efficient scheduling, routing and communication techniques. The energy-efficient techniques at the CPS layer have two classifications, named as virtual machine optimization and Lyapunov optimization.

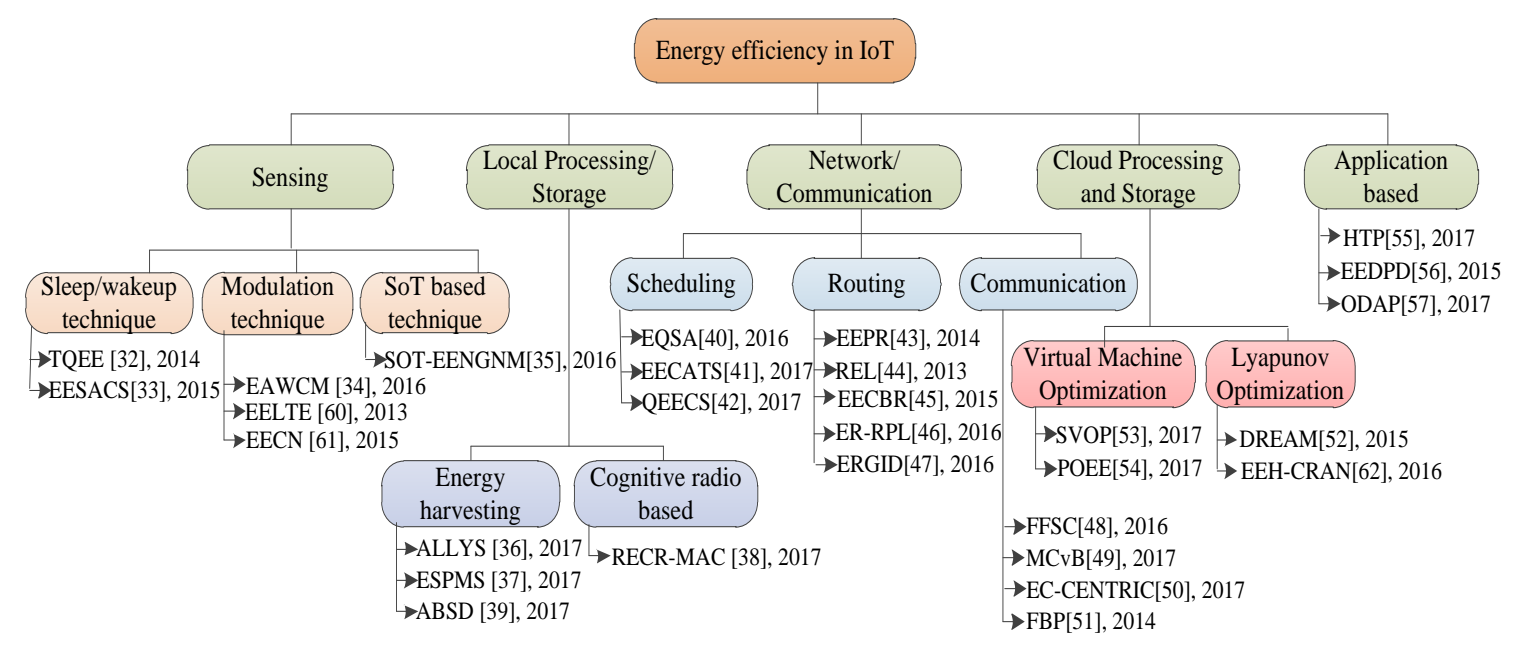

Figure 7. Taxonomy of energy efficient techniques in IoT.

Table 2 lists the nomenclature used in the equations that appear in the sections that follow. 
Table 2. Nomenclature.

\begin{tabular}{|c|c|}
\hline Notation & Description \\
\hline$c^{n}$ & Sensing capability of sensor $n$ \\
\hline$q^{m}$ & Desired QoI of task $m$ \\
\hline$r^{n}$ & Sensory radius \\
\hline$\partial^{m}$ & Variance for sensor $n$ \\
\hline$\beta^{m}$ & Accuracy requirement of task $m$ \\
\hline$r\left(c^{n}, q^{m}\right)$ & Sensor-task relevancy function \\
\hline$E\left(s^{i}, m\right)$ & Maximum residual energy of all possible subset of $m$ activated sensors \\
\hline$v^{j}$ & Normalized residual energy of sensor $s^{j}$ \\
\hline$E^{b}$ & Energy per information bit \\
\hline$R$ & System data rate \\
\hline$E^{t o t}(t)$ & Total energy utilization of the network at time $t$ \\
\hline$\partial$ & Actual coverage area \\
\hline$K(t)$ & Active sensors quantity at time $t$ \\
\hline$p\left[E^{h}=k\right]$ & Probability of harvesting $k$ energy units during $T$ time slots of a frame \\
\hline$E^{h}$ & Amount of harvested energy of a node during a frame \\
\hline$E\left[E^{h}\right]$ & Average harvested energy \\
\hline$E$ & Energy consumption by sensor node \\
\hline$E^{c i r}$ & Energy consumed to operate electrical circuit in the sensor node \\
\hline $\operatorname{Dom}_{\operatorname{Rel}}^{C S_{j}^{i}}$ & Relative dominance of candidate service \\
\hline$E^{a \text { awake }}$ & Total energy spent in awake state \\
\hline$P^{\text {out }}$ & Outage probability \\
\hline $\begin{array}{l}p_{\text {th }}^{\text {out }} \\
L^{i}\end{array}$ & $\begin{array}{l}\text { Maximum outage probability threshold } \\
\text { Lifetime of a node }\end{array}$ \\
\hline$p$ & Forwarding probability of a node \\
\hline$E_{i}$ & Residual energy of node $i$ \\
\hline$E_{\max }$ & Maximum residual energy of node $i$ \\
\hline$E_{t h}$ & Energy threshold \\
\hline$f^{i, s}$ & Traffic generation rate at node \\
\hline$f^{i, d}$ & Traffic arrival rate at node \\
\hline$r^{i j}$ & Traffic departure rate from node $i$ to node $j$ \\
\hline$T^{x y}$ & Delay between two node $x$ and $y$ \\
\hline$T^{M-\sin k}$ & Iterative delay \\
\hline$D_{n}^{t}$ & Expected delay of node \\
\hline$D^{r 0}$ & Total delay of entire network \\
\hline$E_{X}^{r_{0}}$ & Energy consumption of a node $X$ distance away from the sink \\
\hline$E^{r_{0}}$ & Total energy consumption in entire network \\
\hline$\delta\left(C^{i}\right)$ & Energy cost of a component $C^{i}$ \\
\hline$\delta\left(D^{j}\right)$ & Energy consumption of a device \\
\hline$F\left(a^{k}, \beta\right)$ & Lagrangian function of optimization problem \\
\hline$R^{e 2 e}$ & End to end reliability \\
\hline$L$ & Lifetime of whole network under HTP technique \\
\hline$W\left(l_{k}^{i}, n_{k}^{i}\right)$ & Welfare of every user \\
\hline$U\left(l_{k}^{i}, n_{k}^{i}\right)$ & Utility function of user \\
\hline$z$ & Conflict parameter \\
\hline
\end{tabular}

\subsection{Energy Efficient Techniques at Sensing Layer}

In this section, energy efficient techniques at the sensing layer have been described in three categories, namely energy efficient sleep wakeup, modulation and Self Organized Things (SOT) based techniques.

\subsubsection{Energy Efficient Sleep/Wakeup Techniques}

Toward QoI and Energy-Efficiency in Internet-of-Things Sensory Environments (TQEE) [32] has been proposed to manage long term energy consumption under appropriate QoI constraints in diverse applications like environmental monitoring, etc. In this technique, first a novel approach of QoI-aware sensor-to-task relevancy is introduced considering the sensing capabilities of sensors. Then, after 
proposing the technique of critical coverage set of a given task to select the sensors, dynamic decisions for energy consumption optimization are made instantly (Figure 8).

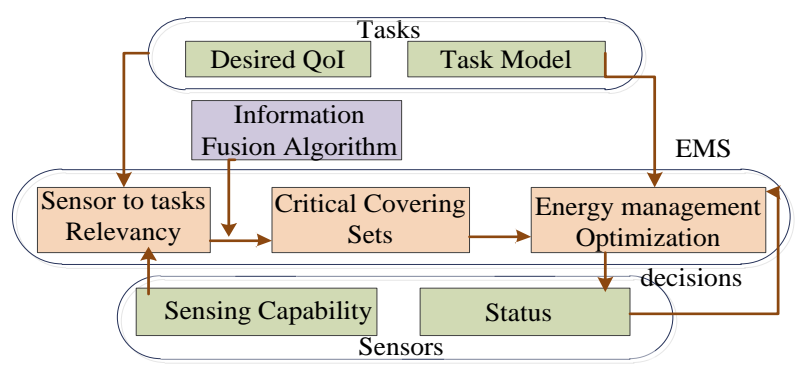

Figure 8. Flow of an energy management framework.

For this model sensor-task relevancy function is formulated as:

$$
r\left(c^{n}, q^{m}\right)=1\left\{\operatorname{dis}\left(X^{n}, Y^{m}\right) \leq r^{n}\right\} \cdot \min \left\{\frac{2 \beta^{m}}{Q\left(\frac{\partial^{m}}{\sqrt{y^{n}}}\right)}\right\}
$$

where $c^{n}, q^{m}, r^{n}, y^{n}, \partial^{m}$ and $\beta^{m}$ are the sensing capability of sensor $n$, desired QoI of task $m$, sensory radius, variance for sensor $n$ and accuracy requirement of task $m$, respectively.

Energy Efficient Sensor Activation for Water Distribution Networks Based on Compressive Sensing (EESACS) [33] has been suggested to optimize energy consumption in IoT applications like water distribution monitoring, intelligent transport systems, smart cities, etc., by activating only a small subset of sensors to sense and transmit in every timeslot, using a scheduling approach based on compressive sensing. Further solutions based on dynamic programming are suggested, after decomposing the scheduling problem into sub-problems. If sensor $s^{i}$ is chosen as activated $m$ are the additional activated sensors out of sensors $s^{i+1}$ to $s^{N}$ where $s^{i}$ and $m$ additional sensors are connected, then the maximum residual energy of all possible subsets of $m$ activated sensors is formulated as:

$$
E\left(s^{i}, m\right)=\left\{\begin{array}{lc}
\max _{s^{j} \in K_{-}^{\prime}\left(s^{i}\right)}\left\{E\left(s^{j}, m-1\right)+v^{j}\right\} & \text { if } K_{-\left(s^{i}\right)}^{\prime} \neq \varnothing \\
-\infty & \text { otherwise }
\end{array}\right.
$$

where $v^{j}$ is the normalized residual energy of sensor $s^{j}$ and $K_{-\left(s^{i}\right)}^{\prime}$ is the set of sensors in the DNS of $s^{i}$ except sink node $s^{r}$. Analysis of the connection between network lifetime and energy consumption has not been done through the proposed technique, and this technique was not tested in various IoT applications such as tunnel and railway monitoring.

\subsubsection{Energy Efficient Modulation Techniques}

Energy-Autonomous Wireless Communication for Millimeter-Scale Internet-of-Things Sensor Nodes (EAWCM) [34] has been suggested to target order of magnitude enhancements in energy efficiency while comprehensively analyzing wireless communication systems. This analysis jointly optimizes different parameters: modulation scheme, node dimension, carrier frequency, Rf/digital/analog circuit specifications, synchronization protocol and a miniaturized 3-D antenna for energy-based ultra-small nodes. In the millimeter-scale node transmission case, if $P^{c k t}$ is the constant power utilization of the power oscillator circuit, then the energy per information bit can be expressed as:

$$
E^{b}=\frac{P^{c k t} K \times T^{p u l s e}}{\left\lceil C^{r}\right\rceil}
$$

and while using three modulation-coding parameters: $T^{\text {pulse }}$ and $C^{r}$, system data rate is formulated as: 


$$
R=\frac{\left\lceil C^{r}\right\rceil}{M T^{\text {pulse }}+(K-1) T^{\text {idle }}+T^{\text {charge }}}
$$

\subsubsection{Energy Efficient Self-Organized Things (SOT)-Based Techniques}

An energy-efficient next generation network management (SOT-EENGNM) [35] has been proposed to minimize the total energy consumption of things and to stabilize the whole coverage area by using an optimization procedure. In this technique, the next generation self-configuration, self-healing and self-optimization procedure of self-organizing network structure of long term evaluation systems is redefined to overcome human dependency in SOT (Figure 9).

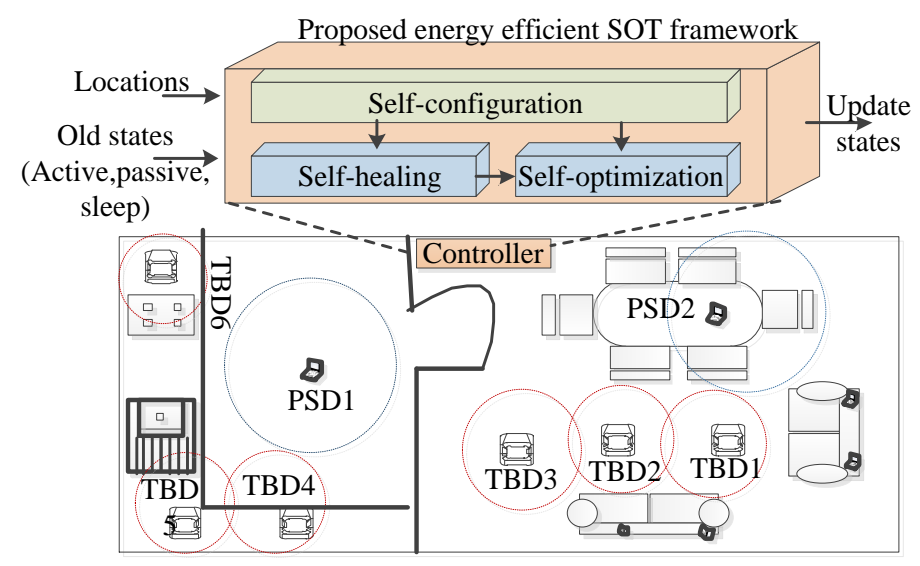

Figure 9. Network topology using SOT.

The spatial distribution of devices to determine active things' distribution in 2D space, and the intersection of device's coverage areas using a conflict parameter are also derived analytically in the self-management process of SOT. If $E^{t o t}(t)$ is the total energy utilization of the network at time $t, K(t)$ is the active sensors quantity at time $t, r$ is coverage radius and $z$ is conflict parameter, then actual coverage area $\partial$ is formulated as:

$$
\partial=\frac{z \times K(t) \times \pi \times r^{2}}{E^{\text {tot }}(t)}
$$

Figure 10a illustrates the energy utilization at particular time $t$ w.r.t. actual coverage area $(\partial)$, while keeping various coverage radius $(r)$ according to Equation (5), while Figure $10 \mathrm{~b}$ shows how when $E^{\text {tot }}(t)$ varies the number of active sensor nodes varies. Summaries of related literatures on energy efficient techniques at the sensing layer are given in Tables 4 and 5, which comprises characteristics/protocol, issues, contributions, techniques, simulation tools used, metrics and research limitations of each paper reviewed.

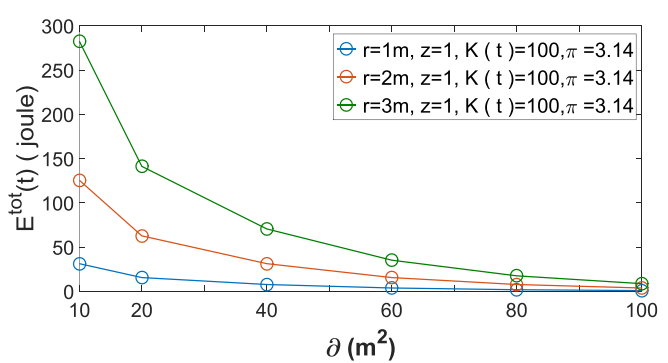

(a)

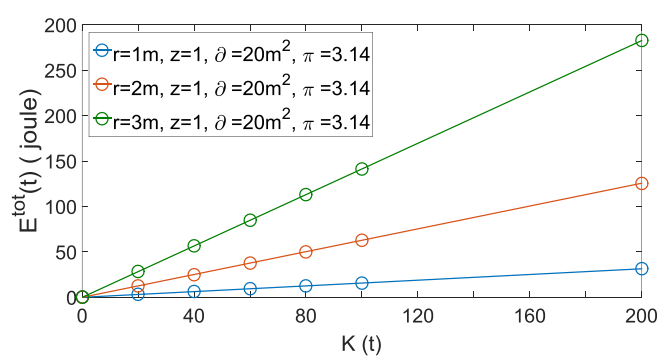

(b)

Figure 10. Representation of Equation (5): (a) total energy utilization via actual coverage area; (b) total energy utilization via number of active sensor nodes. 
Table 3 presents the major abbreviations used in particular in our comparison tables.

Table 3. Abbreviations used in comparison tables.

\begin{tabular}{|c|c|c|c|}
\hline Abbreviation & Description & Abbreviation & Description \\
\hline $\mathrm{CL}$ & Cross-layer & PCV & Photovoltaic cell voltage \\
\hline CA & Context aware & PDR & Packet delivery ratio \\
\hline DL & Delay & CLT & Clustering \\
\hline $\mathrm{EC}$ & Energy consumption & ETX & Expected transmission count \\
\hline $\mathrm{EE}$ & Energy efficiency & BU & Bandwidth Usage \\
\hline DB & Durability & LQ & Link quality \\
\hline CS & Compressive sensing & $\mathrm{EH}$ & Energy harvesting \\
\hline NL & Network lifetime & OP & Outage probability \\
\hline MAC & Medium access control & $\mathrm{RD}$ & Relative dominance \\
\hline CPL & Composite lifetime & OPM & Optimality \\
\hline DC & Duty cycle & ST & Selection time \\
\hline ND & Network distortion & THP & Throughput \\
\hline $\mathrm{ACA}$ & Actual coverage area & L-Ratio & Largest energy cost ratio \\
\hline DPR & Droped packet ratio & PLR & Packet loss rate \\
\hline QoS & Quality of service & T-Ratio & Total saved energy cost ratio \\
\hline $\mathrm{CP}$ & Conflict parameter & $\mathrm{CO}$ & Control overhead \\
\hline QoI & Quality of information & $\mathrm{HC}$ & Hop count \\
\hline NDIB & Number of delivered information bits & PD & Processing density \\
\hline EUS & Energy used per server & AR & Acceptance rate \\
\hline NoM & Number of migrations & PC & Power consumption \\
\hline $\mathrm{CU}$ & CPU utilization & PAR & Peak to average ratio \\
\hline GL & Grid loading & GV & Grid variance \\
\hline
\end{tabular}

Tables 4 and 5 which shows analysis of energy efficient techniques at LPSL. In Table 5, the characteristics of each paper reviewed are categorized into three groups, including protocol/author, approach, and metrics. The protocol/author column comprises abbreviation of techniques and reference. The approach column is categorized into five classes, namely QoI, CS, CL, DC and SOT. The last column represents metrics including DL, EE, DR, SNR, NL, CP, ACA, and DB. Considering Table 5 , the approaches in column four demonstrate that more contributions have been made by duty cycle-based techniques. Further, the metrics column shows that EE is the most considered metric, followed by DR, NL and then ACA for measuring performance of energy efficient techniques at sensing layer. 
Table 4. Summary of energy efficient techniques at sensing layer.

\begin{tabular}{|c|c|c|c|c|c|c|}
\hline $\begin{array}{ll}\text { Protocols } & \text { Characteristics } \\
\end{array}$ & Issues & Contributions & Techniques & Simulators & Metrics & Limitations \\
\hline TQEE & $\begin{array}{l}\text { Energy and data quality } \\
\text { management }\end{array}$ & $\begin{array}{l}\text { Energy efficient and } \\
\text { QoI based solution }\end{array}$ & $\begin{array}{l}\text { QoI-aware sensor-to-task } \\
\text { relevancy using duty cycle }\end{array}$ & Matlab & $\begin{array}{l}-\mathrm{DL} \\
-\mathrm{QoI} \\
-\mathrm{EE}\end{array}$ & $\begin{array}{l}\text { Limited to static } \\
\text { environment }\end{array}$ \\
\hline EESAC & $\begin{array}{l}\text { Problem of more energy } \\
\text { consumption and less } \\
\text { robustness because of } \\
\text { pipeline leakages }\end{array}$ & $\begin{array}{l}\text { Energy efficient and } \\
\text { Robust solution }\end{array}$ & $\begin{array}{l}\text { Compressive sensing based } \\
\text { scheduling approach }\end{array}$ & EPANET & $\begin{array}{l}-\mathrm{NL} \\
-\mathrm{EE}\end{array}$ & $\begin{array}{l}\text { Not applicable to } \\
\text { applications like monitoring } \\
\text { of tunnels and railways }\end{array}$ \\
\hline EAWCM & $\begin{array}{l}\text { Energy optimization because of } \\
\text { unique system constraint by } \\
\text { ultra-small system dimension }\end{array}$ & $\begin{array}{l}\text { Energy optimized } \\
\text { solution. }\end{array}$ & $\begin{array}{l}\text { Cross layer system level } \\
\text { optimization approach }\end{array}$ & - & $\begin{array}{l}-E E \\
-D R \\
-P E R \\
-S N R\end{array}$ & $\begin{array}{l}\text { Error correction has not } \\
\text { been considered. }\end{array}$ \\
\hline SOT-EENGNM & $\begin{array}{l}\text { More human-device interaction } \\
\text { and Energy efficiency }\end{array}$ & $\begin{array}{c}\text { Energy optimized, } \\
\text { Durable and } \\
\text { self-managed solution }\end{array}$ & $\begin{array}{l}\text { Self-Organized Things } \\
\text { based technique }\end{array}$ & - & $\begin{array}{l}-\mathrm{ACA} \\
-\mathrm{CP} \\
-\mathrm{EE} \\
-\mathrm{DR}\end{array}$ & $\begin{array}{l}\text { Parameters such as Delay, } \\
\text { Link stability have not } \\
\text { been considered. }\end{array}$ \\
\hline
\end{tabular}

Table 5. Comparative assessment of energy efficient techniques at the sensing layer.

\begin{tabular}{|c|c|c|c|c|c|c|c|c|c|c|c|c|c|c|}
\hline \multirow{2}{*}{ Protocol/Author } & \multicolumn{5}{|c|}{ Approaches } & \multicolumn{9}{|c|}{ Metrics } \\
\hline & QoI & CS & CL & DC & SoT & DL & EE & DR & SNR & NL & $\mathrm{CP}$ & ACA & PER & DB \\
\hline $\begin{array}{c}\text { TQEE [32] } \\
\text { EESAC [33] } \\
\text { EAWCM [34] } \\
\text { SOT-EENGNM [35] }\end{array}$ & $\sqrt{ }$ & $\sqrt{ }$ & $\sqrt{ }$ & $\begin{array}{l}\sqrt{ } \\
\sqrt{ }\end{array}$ & $\sqrt{ }$ & $\sqrt{ }$ & $\begin{array}{l}\sqrt{ } \\
\sqrt{ } \\
\sqrt{ } \\
\sqrt{ }\end{array}$ & $\begin{array}{l}\sqrt{ } \\
\sqrt{ }\end{array}$ & $\sqrt{ }$ & $\begin{array}{l}\sqrt{ } \\
\sqrt{ }\end{array}$ & $\sqrt{ }$ & $\begin{array}{l}\sqrt{ } \\
\sqrt{ }\end{array}$ & $\sqrt{ }$ & $\sqrt{ }$ \\
\hline
\end{tabular}




\subsection{Energy Efficient Techniques at Local Processing and Storage Layer}

In this section, energy efficient techniques at the local processing and storage layer have been described in two categories, namely energy harvesting and cognitive radio-based techniques.

\subsubsection{Energy Harvesting Techniques}

All You can Send for Energy Harvesting Networks (ALLYS) [36] has been suggested to adjust the transmission probability of nodes based on the residual energy of individual nodes and the network capacity in distributed energy harvesting WSNs-enabled IoT. In ALLYS, a frame of fixed size with adjustable slot transmission probability is used to control the channel access by sink nodes while broadcasting both frame size and transmission probability to reduce the collisions. The probability of harvesting $k$ energy units during $T$ time slots of a frame can be formulated as:

$$
p\left[E^{h}=k\right]=\left(\begin{array}{c}
T \\
k
\end{array}\right)\left(p^{e h, s u c}\right)^{k}\left(1-p^{e h, s u c}\right)^{T-k}
$$

where, $E^{h}$ is the amount of harvested energy of a node during a frame, then average harvested energy is given as:

$$
E\left[E^{h}\right]=\sum_{k=0}^{T} k P\left[E^{h}=k\right]=T p^{e h, s u c}
$$

Efficient Solar Power Management System for Self-Powered IoT Node (ESPMS) [37] is an architecture which achieves higher end-to-end energy efficiency while avoiding linear regulator and presenting a power convertor based on on-chip switched capacitor in IoT system. In the proposed architecture (Figure 11), there are two stages: DC-DC ${ }_{1}$ and DC-DC $C_{2}$ for DC-DC converters between harvesters and loads.

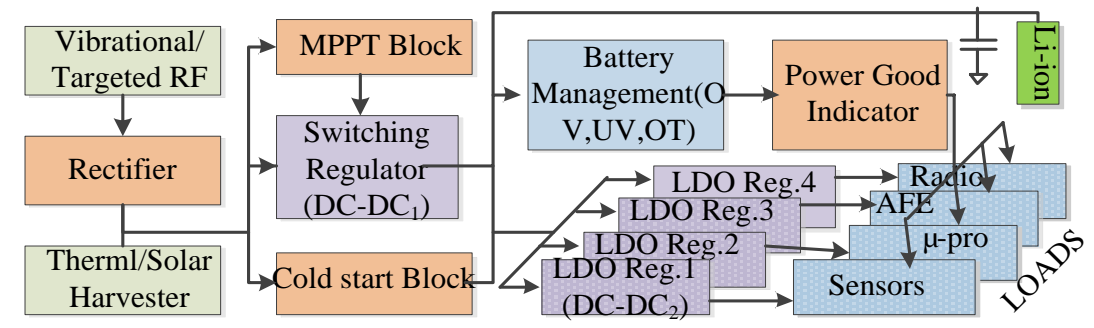

Figure 11. Typical power management architecture in IoT.

Energy harvested roadside IEEE 802.15.4 wireless sensor networks for IoT applications [38] has been suggested while considering different traffic conditions based on the vehicles' movement in WSNs-enabled IoT applications using energy harvesting techniques. To this perspective, an adaptive energy efficient technique (ABSD) has been introduced that adapts MAC parameters related to IEEE 802.15.4 sensor nodes to provide queue occupancy level and to offer traffic levels. EH-ABSD (enhanced form of ABSD) is also introduced by integrating a new MAC parameter (energy backoff) and energy harvesting technique, which improves battery lifetime (energy efficiency), network throughput and QoS values. Energy consumption by sensor node is formulated as:

$$
E=\left\{\left[(1+N) I^{t r}+I^{r c}-(2+N) I^{l s t n}\right] \frac{X^{\text {packet }}}{R}+\left(2^{B O}-2^{S O}\right) I^{\text {sleep }}+2^{S O} I^{l s t n}\right\} U+E^{\text {cir }}
$$

where $E^{c i r}$ is energy consumed to operate electrical circuit in the sensor node, $I^{t r}, I^{r c}, I^{\text {lstn }}$ and $I^{\text {sleep }}$ are electrical current used in transmission, receiving, listening and sleeping mode, respectively. Figure 12 illustrates EHWSN architecture for moving vehicles. 


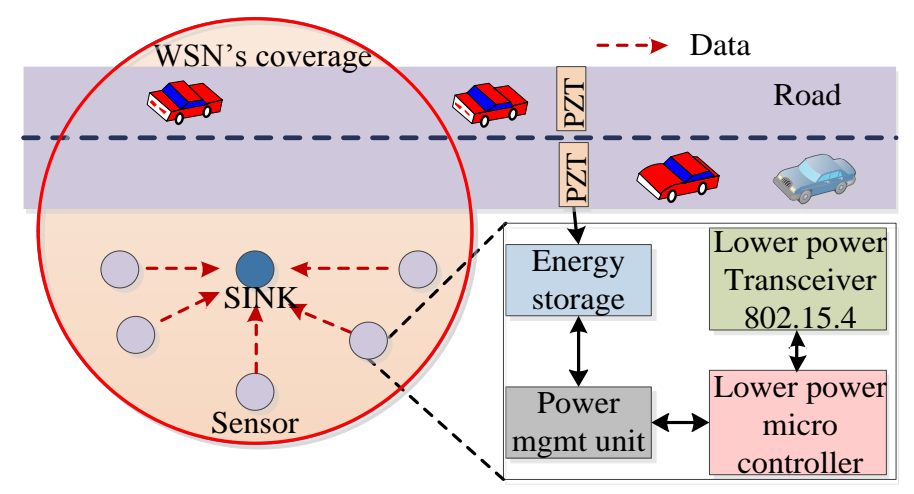

Figure 12. Moving vehicles-based EHWSN architecture.

\subsubsection{Energy Efficient Cognitive Radio Based Techniques}

The energy efficient wireless communication technique based on Cognitive Radio for Internet of Things [38] is a reliable, intelligent, and energy efficient with high throughput and smart cognitive radio-based technique by optimization of control frames and reduction of handshakes quantity across the control and data channels. Reliable and Energy efficient Cognitive Radio Multi-channel Medium Access Control protocol (RECR-MAC) is utilized in various wireless applications that are not delaysensitive such as playing card and chess gaming applications, social media applications like Twitter, and Facebook. Voice over Internet Protocol (VoIP) and mobile users utilize this technique for making free calls.

Summaries of related literatures on energy efficient techniques at the local processing and storage layer is given in Tables 6 and 7, which comprise characteristics/protocol, issues, contributions, techniques, simulation tools used, metrics and research limitations of each paper reviewed.

In Table 7, the characteristics of each paper reviewed are categorized into three groups, including protocol/author, approach, and metrics. The protocol/author column comprises abbreviation of techniques and references. The approach column is categorized into five namely, MAC, EH, CR, DC and QoS. The last column represents metrics, including DL, EE, QoI, BU, NL, PCV, DR, and THP. Considering Table 7, the approaches in columns three and four demonstrate that more contributions have been made by MAC and energy harvesting based techniques, followed by duty cycle based technique. Meanwhile, very few contributions have been made towards CR and QoS techniques. Further, the metrics column shows that EE is the most considered metric, followed by NL and THP, then DL for measuring performance of energy efficient techniques at local computing layer. Tables 8 and 9 present analyses of energy efficient scheduling techniques.4.3. Energy Efficient Techniques at Network/Communication Layer.

In this section, energy efficient techniques at the network/communication layer have been described in three categories, namely energy efficient scheduling, routing and communication techniques. 
Table 6. Summary of energy efficient techniques at local processing and storage layer.

\begin{tabular}{|c|c|c|c|c|c|c|}
\hline $\begin{array}{ll}\text { Protocols } & \text { Characteristics } \\
\end{array}$ & Issues & Contributions & Techniques & Simulators & Metrics & Limitations \\
\hline ALLYS & $\begin{array}{l}\text { Wastage of energy in idle, } \\
\text { listening, overhearing, } \\
\text { collision and retransmissions }\end{array}$ & Limited battery solution & $\begin{array}{l}\text { Energy harvesting and } \\
\text { frame slotted aloha } \\
\text { technique }\end{array}$ & $\begin{array}{l}\text { Qualnet and } \\
\text { VanetMobiSim }\end{array}$ & $\begin{array}{l}-\mathrm{DL} \\
-\mathrm{EE} \\
-\mathrm{THP}\end{array}$ & - \\
\hline RECR-MAC & $\begin{array}{l}\text { Energy consumption and } \\
\text { scarcity of bandwidth }\end{array}$ & $\begin{array}{l}\text { Reliable solution with } \\
\text { high throughput. }\end{array}$ & $\begin{array}{c}\text { Cognitive Radio } \\
\text { Multi-channel MAC } \\
\text { approach }\end{array}$ & $\begin{array}{l}\text { NS-2 and SUMO } \\
\text { EvalVid }\end{array}$ & $\begin{array}{l}-\mathrm{BU} \\
-\mathrm{THP} \\
-\mathrm{EE} \\
-\mathrm{DR}\end{array}$ & $\begin{array}{l}\text { Not applicable in the } \\
\text { applications those are } \\
\text { delay sensitive. }\end{array}$ \\
\hline ABSD & $\begin{array}{l}\text { Excess energy consumption } \\
\text { in receiving, transmitting, } \\
\text { idle listening and sleeping }\end{array}$ & $\begin{array}{l}\text { Energy efficient and } \\
\text { QoS aware solution }\end{array}$ & $\begin{array}{l}\text { MAC aware Energy } \\
\text { harvesting approach }\end{array}$ & $\begin{array}{l}\text { OPNET and } \\
\text { MatLab }\end{array}$ & $\begin{array}{l}\text {-EE } \\
-\mathrm{THP} \\
-\mathrm{QOS} \\
-\mathrm{DPR}\end{array}$ & $\begin{array}{l}\text { Vital parameters such } \\
\text { as PSNR has not been } \\
\text { considered. }\end{array}$ \\
\hline
\end{tabular}

Table 7. Comparative assessment of energy efficient techniques at local processing and storage layer.

\begin{tabular}{|c|c|c|c|c|c|c|c|c|c|c|c|c|c|c|}
\hline \multirow{2}{*}{ Protocol/Author } & \multicolumn{5}{|c|}{ Approaches } & \multicolumn{9}{|c|}{ Metrics } \\
\hline & MAC & EH & CR & DC & QoS & DL & EE & QoI & BU & NL & PCV & DR & DPR & THP \\
\hline $\begin{array}{l}\text { ALLYS [36] } \\
\text { ESPMS [37] }\end{array}$ & $\sqrt{ }$ & $\begin{array}{l}\sqrt{ } \\
\sqrt{ }\end{array}$ & & $\sqrt{ }$ & & $\sqrt{ }$ & $\sqrt{ }$ & & & $\sqrt{ }$ & 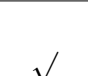 & & & $\sqrt{ }$ \\
\hline RECR-MAC [38] & $\sqrt{ }$ & & $\sqrt{ }$ & & & & $\sqrt{ }$ & & $\sqrt{ }$ & $\sqrt{ }$ & & $\sqrt{ }$ & & $\sqrt{ }$ \\
\hline ABSD [39] & $\sqrt{ }$ & $\sqrt{ }$ & & $\sqrt{ }$ & $\sqrt{ }$ & $\sqrt{ }$ & $\sqrt{ }$ & & & $\sqrt{ }$ & & & $\sqrt{ }$ & $\sqrt{ }$ \\
\hline
\end{tabular}


Table 8. Summary of energy efficient scheduling techniques.

\begin{tabular}{|c|c|c|c|c|c|c|}
\hline $\begin{array}{ll}\text { Protocols } & \text { Characteristics } \\
\end{array}$ & Issues & Contributions & Techniques & Simulators & Metrics & Limitations \\
\hline EQSA & $\begin{array}{l}\text { Energy and QoS aware } \\
\text { service selection }\end{array}$ & $\begin{array}{l}\text { Energy and QoS } \\
\text { aware solution }\end{array}$ & $\begin{array}{l}\text { lexicographic optimization } \\
\text { and QoS constraints } \\
\text { relaxation approach }\end{array}$ & JVM, JRE 1.6 & $\begin{array}{c}\text {-EC } \\
\text {-QoS } \\
\text {-CPL } \\
\text {-OPM } \\
\text {-RD } \\
\text {-ST }\end{array}$ & $\begin{array}{l}\text { Limited to static } \\
\text { environment }\end{array}$ \\
\hline EECATS & $\begin{array}{l}\text { Dynamic service quality } \\
\text { requirement with variable } \\
\text { quality information in } \\
\text { multi hop communication }\end{array}$ & $\begin{array}{l}\text { Energy and context } \\
\text { aware solution }\end{array}$ & $\begin{array}{l}\text { Energy efficient and context } \\
\text { aware traffic scheduling }\end{array}$ & $\begin{array}{l}\text { NS2 and } \\
\text { Contiki OS }\end{array}$ & $\begin{array}{l}\text {-EE } \\
-\mathrm{DL} \\
-\mathrm{DR} \\
-\mathrm{THP} \\
-\mathrm{CA}\end{array}$ & $\begin{array}{l}\text { Overload and link quality } \\
\text { have not been considered }\end{array}$ \\
\hline QEECS & $\begin{array}{c}\text { Maintain tradeoff } \\
\text { between energy } \\
\text { consumption and QoS. }\end{array}$ & $\begin{array}{l}\text { Energy efficient Qos } \\
\text { aware solution for } \\
\text { industrial applications }\end{array}$ & $\begin{array}{l}\text { QPSO, TDMA scheduling, } \\
\text { NSGA-2 }\end{array}$ & MATLAB & $\begin{array}{l}\text {-EE } \\
-\mathrm{NL} \\
-\mathrm{OP} \\
-\mathrm{QoS}\end{array}$ & $\begin{array}{l}\text { Delay is not considered. } \\
\text { Analysis of the clustering } \\
\text { performance is } \\
\text { not performed. }\end{array}$ \\
\hline
\end{tabular}

Table 9. Comparative assessment of energy efficient scheduling techniques.

\begin{tabular}{|c|c|c|c|c|c|c|c|c|c|c|c|c|c|c|}
\hline \multirow{2}{*}{ Protocol/Author } & \multicolumn{5}{|c|}{ Approaches } & \multicolumn{9}{|c|}{ Metrics } \\
\hline & MAC & CLT & CA & DC & QoS & DL & EE & OPM & RD & NL & OP & DR & CPL & THP \\
\hline $\begin{array}{c}\text { EQSA [40] } \\
\text { EECATS [41] } \\
\text { QEECS [42] }\end{array}$ & $\begin{array}{l}\sqrt{ } \\
\sqrt{ }\end{array}$ & $\sqrt{ }$ & $\sqrt{ }$ & $\begin{array}{l}\sqrt{ } \\
\sqrt{ }\end{array}$ & $\begin{array}{l}\sqrt{ } \\
\sqrt{ } \\
\sqrt{ }\end{array}$ & $\begin{array}{l}\sqrt{ } \\
\sqrt{ }\end{array}$ & $\begin{array}{l}\sqrt{ } \\
\sqrt{ } \\
\sqrt{ }\end{array}$ & $\sqrt{ }$ & $\sqrt{ }$ & $\begin{array}{l}\sqrt{ } \\
\sqrt{ }\end{array}$ & $\sqrt{ }$ & $\sqrt{ }$ & $\sqrt{ }$ & $\sqrt{ }$ \\
\hline
\end{tabular}




\subsection{Energy Efficient Techniques at Network/Communication Layer}

\subsubsection{Energy Efficient Scheduling Techniques}

Energy-Centered and QoS-Aware Services Selection for Internet of Things (EQSA) [40] utilizes lexicographic optimization and QoS constraints relaxation approaches to preselect QoS-aware services required for the user's level and the technique of relative dominance of services in the Pareto sense to minimize energy usage for a composite service in the IoT environment. The relative dominance of candidate services is dependent on QoS attributes, energy profile (EP) and user's preferences and calculated as:

$$
\operatorname{Dom}_{\mathrm{Rel}}^{C S_{j}^{i}}=E P-\operatorname{Dom}^{C S_{j}^{i}} \sum_{q=1}^{\operatorname{QoS}} \operatorname{Dom}^{\left(C S_{j}^{i}, q\right)} \times \operatorname{Pref} q
$$

where $\sum_{q=1}^{Q o S} \operatorname{Dom}^{\left(C S_{j}^{i}, q\right)} \times$ Prefq is QoS-based dominance of the service $C S_{j}^{i}$. Energy Efficient Context Aware Traffic Scheduling for IoT applications (EECATS) [41] has been proposed to realize energy-efficient resource allocation in Wi-Fi-based devices in heterogeneous traffic demand and distinct weighted quality classes-based multi-hop IoT infrastructures. In this technique, service quality requirements and a context priority-based optimization model by sub-gradient projection method is introduced. In the awake state, the total energy spent is formulated as:

$$
E^{a w a k e}=P^{t x} \times T^{a w, l}=P^{t x} \times\left(\sum_{i=1, j=1}^{n} A_{i, j}\left(2 \times n \times T^{t, i}+3 \times T^{s f s}+T^{p f}+T^{w a i t}\right)\right)
$$

QoS-Aware Energy-Efficient Cooperative Scheme for Cluster-Based IoT Systems (QEECS) [42] has been suggested to provide tradeoff between energy efficiency and QoS provisioning by formulating a multi objective optimization problem, while using network lifetime and outage probability as metric, respectively. This technique considers two phases for data transmission: setup phase and steady state phase. During the setup phase a combination of quantum-inspired particle swarm optimization and exhaustive search for selecting optimum cooperative coalition for cluster head $(\mathrm{CH})$ and cooperative nodes (Coop) in capillary network of industrial IoT systems. In steady state phase, collection and transmission of data by all nodes is divided into three stages using TDMA scheduling, data collection, local broadcasting and long-haul cooperative transmission. The multi objective optimization problem is solved using improved non-dominated sorting genetic algorithm (NSGA-2). Finally, the combination of QPSO and NSGA-2 algorithms obtains the Pareto-optimal solution first. For QoS provisioning, formula for the outage probability is mentioned as:

$$
P^{\text {out }}=p_{\text {th }}^{\text {out }}-P^{\text {out }, \frac{C H}{\mathrm{Coop}}}
$$

where $p_{t h}^{\text {out }}$ is the maximum outage probability threshold. Lifetime of a node is formulated as:

$$
L^{i}=\frac{E^{r e s}}{E}
$$

$E$ is the energy consumption of a node, if $p_{d c}, p_{l b}$ and $p_{l h}$ are power consumption in data collection, local broadcasting and local-haul cooperative transmission phase respectively, then $E$ is described by a formula as:

$$
E=\frac{1}{\alpha} \times p_{d c}+\frac{1}{2 \alpha} \times p_{l b}+\frac{1}{2 \alpha} \times p_{l h}
$$

Figure 13 illustrates the system model of QEECS technique. A summary of related literatures on energy efficient scheduling techniques is given in Tables 8 and 9, which comprises characteristics/protocol, issues, contributions, techniques, simulation tools used, metrics and research limitations of each paper reviewed. 


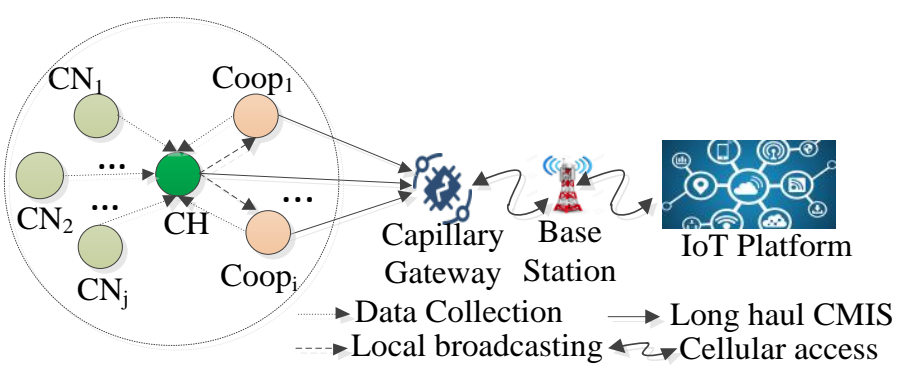

Figure 13. System model.

In Table 9, the characteristics of each paper reviewed are categorized into three classes, including protocol/author, approach, and metrics. The protocol/author column comprises abbreviation of techniques and reference. The approach column is categorized into five namely, MAC, CLT, CA, DC and QoS. Last column represents metrics including DL, EE, OPM, RD, NL, OP, DR, COL and THP. Considering Table 9, the approaches in column five demonstrate that more contributions have been made by QoS based techniques, followed by MAC and duty cycle based techniques. Meanwhile, very few contributions have been made towards clustering and context aware techniques. Further, metrics column shows that EE is the most considered metric, followed by NL and DL, then THP for measuring performance of energy efficient scheduling techniques.

\subsubsection{Energy Efficient Routing Techniques}

Energy-efficient probabilistic routing (EEPR) [43] has been suggested to control the transmission of routing packets randomly using flooding technique while enhancing the network lifetime and minimizing the packet loss rate. EEPR utilizes two metrics: expected transmission count and residual energy of every node simultaneously in the context of typical ad-hoc on demand vector protocol. While using the expected transmission count metric, EEPR composes the routing route with better link quality, while using the residual energy of every node as a routing metric makes it possible the utilization of energy more evenly for all the IoT nodes across the network. The transmission count metric is induced not by using the heuristic method but by using the bit error rate based on the path-loss model. The second routing matric used is residual energy which results in even use of it among all the nodes (Figure 14). Then, the forwarding probability $p$ of a node under the proposed EEPR algorithm is determined as:

$$
\begin{gathered}
p=\left[P_{\text {min }}+E_{i} A\left[1+\frac{\left(E T X_{(i-1, i)}-E T X_{\max }\right)}{\left(1-E T X_{\max }\right)}\right]\right]^{1 / \alpha}, \\
A=\frac{1-P_{\min }}{2 \times E_{\max }}
\end{gathered}
$$

where $E_{i}$ and $E_{\max }$ are residual energy and maximum residual energy of node $i$, and $P_{\min }$, and $\propto$ are predefined minimum forwarding probability, and the weighted factor for variation of $p$ respectively. The forwarding probability is better, with high residual energy of the node and low ETX value of the link, but in case of far lower ETX value of link and less residual energy of the node, the forwarding probability is low. 


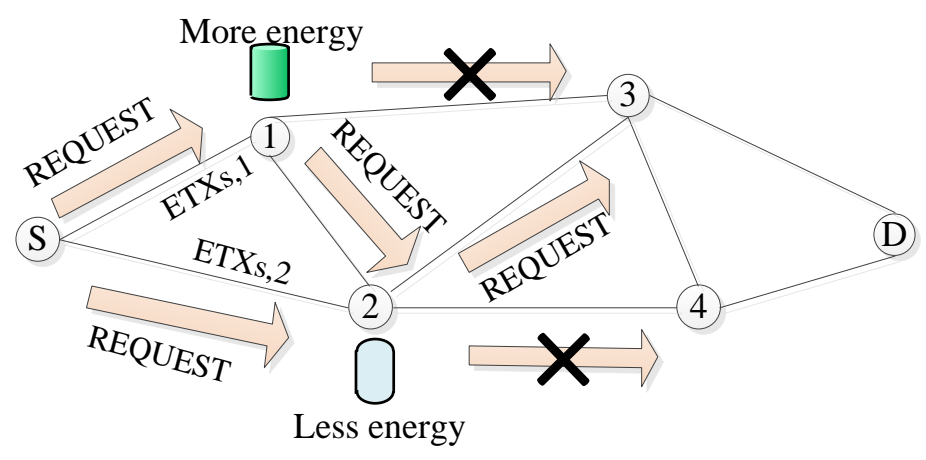

Figure 14. EEPR algorithm.

EEPR algorithm results in slightly more route setup delay and slightly lesser routing success probability. EEPR does not consider the delay. Equation (14) has been illustrated by Figure 15. Figure 15a shows that how forwarding probability of a node varies as $E T X_{(i-1, i)}$ varies in Equation (14), while Figure $15 \mathrm{~b}$ shows the relation between forwarding probability and residual energy of node $i$. Here $E_{\max }$ has been considered as 100 joule to calculate $A$.

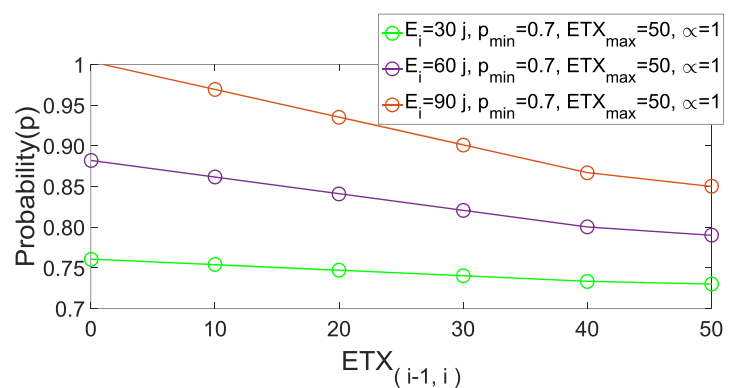

(a)

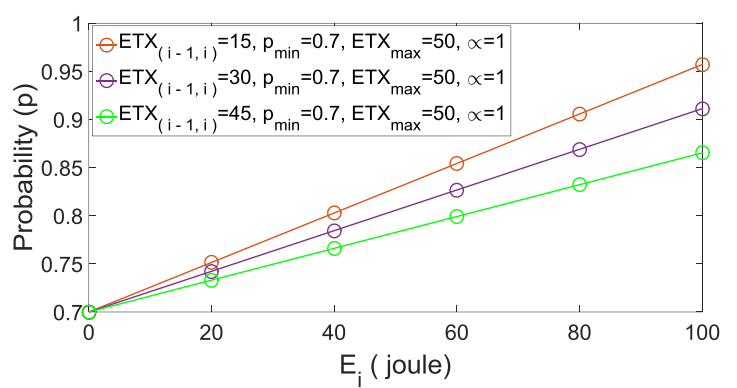

(b)

Figure 15. Representation of equation 14: (a) forwarding probability of a node via $E T X_{(i-1, i)}$; (b) forwarding probability via residual energy of node $i$.

Routing protocol based on Energy and Link quality (REL) [44] is based on optimization of the route selection mechanism while utilizing link quality estimation, energy evaluation, hop count and load balancing mechanisms, so it increases the system's reliability and prevents premature death of nodes. REL uses three metrics: residual energy, link quality based on weak links, and hop count to minimize long and inefficient paths. For the route selection process, there are two threshold values: first threshold is $E_{t h}$ (energy threshold) used in load balancing technique and finding route. The second threshold is HCdiffer max_allow (maximum-hop-count-difference) which calculates the maximum difference of hops to the present route. The prime technique of fault tolerance and load balancing in WSNs/IoT applications is the usage of multiple routes to control traffic across various paths. By using multiple routes, throughput and data reliability can be increased by balancing utilized energy and bandwidth aggregation. In REL, route selection is processed on the basis of three rules. If $R_{a}$ is current route and $R_{b}$ is alternative route and $E_{t h}$ is energy threshold then both routes are compared based on the metrics and there is a switch from $R_{a}$ to $R_{b}$ if the comparison satisfied the rules described below:

1. $\quad R_{a}$ energy $=R_{b}$ energy, $R_{a}$ hopcount $=R_{b}$ hopcount + HCdiffer max $\_$allow and $R_{a}$ weak links $=R_{b}$ weak links

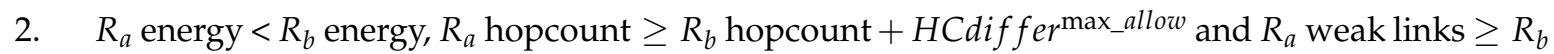
weak links 
3. $R_{a}$ energy $>R_{b}$ energy, $R_{a}$ energy $\leq R_{b}$ energy $+E_{t h}, R_{a}$ hopcount $>R_{b}$ hopcount + HCdiffer ${ }^{\text {max } \_a l l o w}$ and $R_{a}$ weak links $\geq R_{b}$ weak links

REL selects a route with good link quality and efficient energy consumption, but has the disadvantage of less routing success probability and more route set-up delay. This protocol is applicable only for static environments. For energy saving the radio transmission technique can be used.

Energy-Efficient Content-Based Routing (EECBR) [45] is a routing technique for publishing/ subscribing approaches that comprises routing based on context and content. The EECBR protocol tackles the routing problem while balancing the consumption of energy in efficient manner across an IoT network. First of all, a virtual topology is created, which can be a tree or the set of clusters depending upon the network's topology. In this algorithm, the sensor which covers the maximum sets of sensors of interest that are located in the communication range, is selected as a leader from a set of sensors of interest for a particular event. Compared with many other protocols it schedules and decides sleep/awake sensors by monitoring a certain area by using some leaders. The virtual topology helps in organizing sensors and reducing their communication cost across the IoT network. While making decisions on the selection of the leaders, the contribution of every sensor is evaluated, which depends on the quantity of uncovered sensors that are interested in a particular event/uncovered leaders of $(i-1)$ th level located within the range of the sensors, and the residual energy of sensors. The sensor with the largest contribution is selected as a leader. Intended receivers are broadcasted by enabling it.

An Energy-Efficient Region-Based RPL Routing Protocol for Low-Power and Lossy Networks (ER-RPL) [46] has been suggested to achieve energy-efficient point to point data delivery while considering reliability in machine to machine communication for static, low-power and lossy networks. ER-RPL utilizes only a subset of nodes from some regions, in place of all nodes, for finding optimal route in terms of efficient energy consumption and reliability.

ER-RPL has been described in two stages: network initialization stage and route discovery stage. In the network initialization stage, the first coordinates of each reference node are computed, then based on reference node's coordinate values and hop counts, every node estimates its distance to every reference node. By using a distributed self-regioning technique, the region of a node in the network is computed. In the route discovery stage, based on the region of the source node and destination node, route discovery is processed among the subset of nodes using region-based route discovery. Then, region-based route discovery is enhanced, by designing region to region routing without route discovery. Besides, the region to region route is further shortened by implementing a route adjustment on-the-fly algorithm and the dead zone problem is solved by an adaptive region selection algorithm. If $f^{i, s}$ is traffic generation rate at node $i, f^{i, d}$ is traffic arrival rate at destination node $i, r^{i j}$ is traffic departure rate from node $i$ to node $j$. Then, in ER-RPL, formula for point to point traffic model of node is mentioned below:

$$
f^{i, s}+\sum_{j \in N N(i)} \partial^{j i} r^{j i}-\sum_{j \in N N(i)} \partial^{i j} r^{i j} p^{i j}=f^{i, d}
$$

where $0 \leq r^{j i} \leq C^{j i}, \forall_{i, j \in n}$, and $i \neq j$. If network running time is $T$, traffic generation rate at time $t$ is $f^{i, s, t}$, traffic arrival rate at destination node $i f^{i, d, t}$ and duration of traffic flow is $d t$, then traffic load at node $i$ is formulated as:

$$
\begin{aligned}
& \int_{0}^{T} f^{i, s, t} d t_{i}=L^{i 0}+L^{i 1}+\ldots+L^{i N}=\sum_{0 \leq j \leq N} L^{i j} \\
& \int_{0}^{T} f^{i, d, t} d t_{i}=L^{i 0}+L^{i 1}+\ldots+L^{i N}=\sum_{0 \leq j \leq N} L^{j i}
\end{aligned}
$$

ER-RPL supports generic traffic patterns, network scalability and robustness in different wireless channel condition. It discovers energy efficient and reliable routing paths, but is not suitable in a 
dynamic environment. An Efficient Routing Protocol for Emergency Response Internet of Things (ERGID) [47] has been suggested on the basis of global information decision to enhance reliability, to minimize delay and to provide load balancing in the network. In ERGID, a delay iterative method is used for optimizing delay estimation and residual energy probability choice approach is utilized for balancing the network load. The delay iterative method is based on a Dijkstra algorithm for finding the shortest path. The delay between two nodes $\mathrm{x}$ and $\mathrm{y}$ is calculated as:

$$
T^{x y}=\frac{\left(T^{x}-T S\right)}{2}
$$

where $T^{x}$ and TS are the current time of node $x$ and time stamp, respectively, and the iterative delay is calculated as:

$$
T^{M-s i n k}=\min _{x \in R M}\left\{T^{M x}+T^{x-\sin k}\right\}
$$

According to the residual energy probability choice approach, if $E^{x}$ is the residual energy of node $x$ and $\mathrm{CN}$ is the set of nodes having a delay to the sink smaller than the residual time, then the forwarding probability for every candidate node is formulated as:

$$
P^{x}=\frac{E^{x}}{\sum_{j \in C N} E^{j}, x \in C N}
$$

ERGID is limited to small-scale emergency response IoT due to its energy consumption, and not focused on large-scale applications. A summary of related literatures on energy efficient routing techniques is given in Tables 10 and 11, which comprises characteristics/protocol, issues, contributions, techniques, simulation tools used, metrics and research limitations of each paper reviewed.

In Table 11, the characteristics of each paper reviewed are categorized into three classes including protocol/author, approach, and metrics. The protocol/author column comprises abbreviations of techniques and reference. The approach column is categorized into five groups namely, SR, PA, PSS, CA and QoS. The last column represents metrics including DL, EE, LQ, ETX, NL, HC, PLR, PDR and CO. Considering Table 11, the approaches in columns two and five demonstrate that more contributions have been made by PA and QoS based techniques, followed by SR, PSS and CA techniques. Further, the metrics column shows that EE is the most considered metric, followed by DL, then LQ, NL, HC and PDR for measuring performance of energy efficient routing techniques. 
Table 10. Summary of energy efficient routing techniques.

\begin{tabular}{|c|c|c|c|c|c|c|c|}
\hline Protocols & Characteristics & Issues & Contributions & Techniques & Simulators & Metrics & Limitations \\
\hline & EEPR & $\begin{array}{l}\text { Network partitioning and } \\
\text { Energy consumption in } \\
\text { distributed network }\end{array}$ & $\begin{array}{l}\text { Evenly consumption of } \\
\text { energy by each node and } \\
\text { enhanced network lifetime }\end{array}$ & $\begin{array}{c}\text { Energy efficient } \\
\text { probabilistic routing }\end{array}$ & $\begin{array}{l}\text { NS-2 on Linux } \\
\text { fedora } 13\end{array}$ & $\begin{array}{l}\text {-ETX } \\
-\mathrm{EE} \\
-\mathrm{LQ} \\
-\mathrm{NL}\end{array}$ & $\begin{array}{l}\text { Delay is not considered } \\
\text { Routing success } \\
\text { probability is less and } \\
\text { route setup delay is high }\end{array}$ \\
\hline & REL & $\begin{array}{l}\text { Restriction of sensor } \\
\text { nodes in terms of energy, } \\
\text { processing and memory. }\end{array}$ & $\begin{array}{l}\text { Evenly distribution of } \\
\text { network resources, } \\
\text { enhanced lifetime and QoS }\end{array}$ & $\begin{array}{l}\text { Routing protocol } \\
\text { based on energy and } \\
\text { link quality. }\end{array}$ & $\begin{array}{l}\text { OMNET++ with } \\
\text { Castalia framework }\end{array}$ & $\begin{array}{c}\text {-EE } \\
\text {-LQ } \\
-\mathrm{HC} \\
-\mathrm{NL} \\
-\mathrm{PDR} \\
\text {-DL }\end{array}$ & $\begin{array}{c}\text { Not managed } \\
\text { radio/transmissions to } \\
\text { improve energy saving }\end{array}$ \\
\hline & EECBR & $\begin{array}{c}\text { Energy consumption } \\
\text { challenge in asynchronous } \\
\text { communication }\end{array}$ & $\begin{array}{l}\text { Enhanced lifetime and less } \\
\text { energy consumption }\end{array}$ & $\begin{array}{l}\text { Publish/subscribe } \\
\text { scheme based on } \\
\text { content based routing }\end{array}$ & OMNET++ & $\begin{array}{l}-\mathrm{EE} \\
-\mathrm{NL}\end{array}$ & $\begin{array}{c}\text { QoS parameter such as } \\
\text { delay is not considered. } \\
\text { Cross layer approach is } \\
\text { not utilized }\end{array}$ \\
\hline & ER-RPL & $\begin{array}{l}\text { Energy efficiency, } \\
\text { reliability, dead } \\
\text { zone problem }\end{array}$ & $\begin{array}{l}\text { Energy efficient, reliable } \\
\text { and robust solution. }\end{array}$ & $\begin{array}{l}\text { Distributed } \\
\text { self-regioning } \\
\text { technique }\end{array}$ & NS-3 & $\begin{array}{c}\text {-DL } \\
-\mathrm{PDR} \\
-\mathrm{EC} \\
-\mathrm{HC} \\
-\mathrm{CO}\end{array}$ & $\begin{array}{c}\text { Not working in } \\
\text { dynamic environment. }\end{array}$ \\
\hline & ERGID & $\begin{array}{l}\text { Assurance of real } \\
\text { time emergency } \\
\text { response ability }\end{array}$ & $\begin{array}{l}\text { Reliable data transmission } \\
\text { and energy efficient } \\
\text { emergency response in IoT }\end{array}$ & $\begin{array}{l}\text { Emergency response } \\
\text { IoT based on global } \\
\text { information decision. } \\
\text { REPC and DIM }\end{array}$ & NS-2 & $\begin{array}{l}-\mathrm{DL} \\
-\mathrm{EE} \\
-\mathrm{PLR}\end{array}$ & $\begin{array}{l}\text { Limited to small-scale } \\
\text { emergency response IoT } \\
\text { for energy consumption }\end{array}$ \\
\hline
\end{tabular}

Table 11. Comparative assessment of energy efficient routing techniques.

\begin{tabular}{|c|c|c|c|c|c|c|c|c|c|c|c|c|c|c|}
\hline \multirow{2}{*}{ Protocol/Author } & \multicolumn{5}{|c|}{ Approaches } & \multicolumn{9}{|c|}{ Metrics } \\
\hline & SR & PA & PSS & CA & QoS & DL & EE & LQ & ETX & NL & $\mathrm{HC}$ & PLR & PDR & $\mathrm{CO}$ \\
\hline EEPR [43] & & $\sqrt{ }$ & \multirow{5}{*}{$\sqrt{ }$} & \multirow{5}{*}{$\sqrt{ }$} & & & $\sqrt{ }$ & $\sqrt{ }$ & $\sqrt{ }$ & $\sqrt{ }$ & & & & \\
\hline REL [44] & & $\sqrt{ }$ & & & $\sqrt{ }$ & $\sqrt{ }$ & $\sqrt{ }$ & $\sqrt{ }$ & & $\sqrt{ }$ & $\sqrt{ }$ & & $\sqrt{ }$ & \\
\hline EECBR [45] & & & & & & & $\sqrt{ }$ & & & & & & & \\
\hline ER-RPL [46] & $\sqrt{ }$ & $\sqrt{ }$ & & & $\sqrt{ }$ & $\sqrt{ }$ & $\sqrt{ }$ & & & & $\sqrt{ }$ & & $\sqrt{ }$ & $\sqrt{ }$ \\
\hline ERGID [47] & & & & & $\sqrt{ }$ & $\sqrt{ }$ & $\sqrt{ }$ & & & & & $\sqrt{ }$ & & \\
\hline
\end{tabular}




\subsubsection{Energy Efficient Communication Techniques}

An Energy Efficiency Communications Approach for Delay Minimizing in Internet of Things [48] optimizes end-to-end delay and network lifetime from a theoretical perspective and establishes the relationships between the minimum per-hop forwarding distance $r_{0}$, the transmission range $r$, the node density $\rho$ and the duty cycle that affect the node energy and network delay as well as the network lifetime. Liu et al. suggested a technique called Fast data collection for the node Farthest away from the sink and Slow data collection for the node Closest to the Sink (FFSC) that adopts a direct forwarding routing technique for nodes located at a large distance from the sink after determining the availability of forwarding nodes. In the region near the sink, which has higher energy constraints, data is only forwarded after the selection of the optimal relay node to minimize energy consumption and enhance network lifetime. FFSC saves energy of node and minimizes delay using a duty cycle technique. If the number of forwarding set nodes for a node is $n$ and duty length is $t$, then the duty cycle of every node is $\frac{1}{t}$, and the expected delay of nodes is calculated as:

$$
D_{n}^{t}=\sum_{i=0}^{t-2} i\left(1-\frac{1}{t}\right)^{i n}\left[1-\left(1-\frac{1}{t}\right)^{n}\right]+(t-1)\left(1-\frac{1}{t}\right)^{(t-1) n}
$$

Total delay of the entire network can be formulated as:

$$
D^{r_{0}}=2 \pi \int_{0}^{R}\left[\frac{X}{\epsilon_{X}^{r_{0}}}\right]\left(\sum_{i=0}^{t-2} i\left(1-\frac{1}{t}\right)^{i n_{d}^{r_{0}}}\left[1-\left(1-\frac{1}{t}\right)^{n_{d}^{r_{0}}}\right]+(t-1)\left(1-\frac{1}{t}\right)^{(t-1) n_{d}^{r_{0}}}\right) X d_{X}
$$

where $d$ and $X$ are the distance from source to sink, and the distance of particular node from the sink, respectively. $\epsilon_{X}^{r_{0}}$ is expected reward of each hop. Energy consumption of a node $X$ distance away from the sink is formulated as:

$$
E_{X}^{r_{0}}=P_{L P L}^{X} t+P_{R}^{X} \varnothing_{R}^{r x}+P_{T}^{X} \varnothing_{T}^{r x}
$$

where $P_{L P L}^{X}, P_{R}^{X}, P_{T}^{X}$ and $\varnothing_{R}^{r x}$ are the power associated with low power listening operation of node, average power to transmit a packet, power used to receive a packet and amount of data loaded by node. Considering $\varnothing_{T}^{r x}=\varnothing_{R}^{r x}+1$, Therefore total energy consumption in the entire network is expressed as:

$$
E^{r_{0}}=2 \pi \int_{0}^{R} E_{X}^{r_{0}} X d_{X}
$$

Bacterial Relay for Energy Efficient Molecular Communications (MCvB) [49] has been proposed to deliver information while considering energy efficiency using bacterial mobile relays for molecular communication in the Internet-of-Nano-Things. This technique first derives the probability of end-to-end delivery using a propagation model of information pickup and information delivery stages after introducing system parameters.

This provides an energy model while deriving an energy efficiency expression considering all communication stages. These communication stages are: encoding, encapsulation, propagation, decapsulation and decoding (Figure 16). If $E^{\text {tot }}$ is energy consumption for whole communication mechanism including these all stages as:

$$
E^{\text {tot }}=N \times E^{p}+M \times E^{b}+K \times E^{m} \times T+J \times\left(E^{d}+E^{e}\right)
$$

where $N \times E^{p}$ is the total energy consumption in encoding stages, having $N$ plasmids, $M \times E^{b}$ is energy consumption in encapsulation stage having $M$ plasmids, $K \times E^{m} \times T$ energy consumption in propagation stages and $J \times\left(E^{d}+E^{e}\right)$ is the energy consumption in the decapsulation and decoding stage. This technique has a drawback in the case of delay tolerant and short distance communication.

An Energy- and Context-Centric Perspective on IoT Systems and Protocol Design (EC-CENTRIC) [50] has been proposed to provide an optimization framework that analyzes basic functionalities of IoT systems in terms of energy and context. The process of this framework is divided in three technical aspects: providing a balance between communication tasks and processing 
techniques dependent on signal-like feature extraction and compression, enhancing network lifetime while designing routing and channel access protocols jointly, and adopting appropriate learning architecture and reconfigurable techniques to provide self-adaptability in various operating conditions as presented in Figure 17.

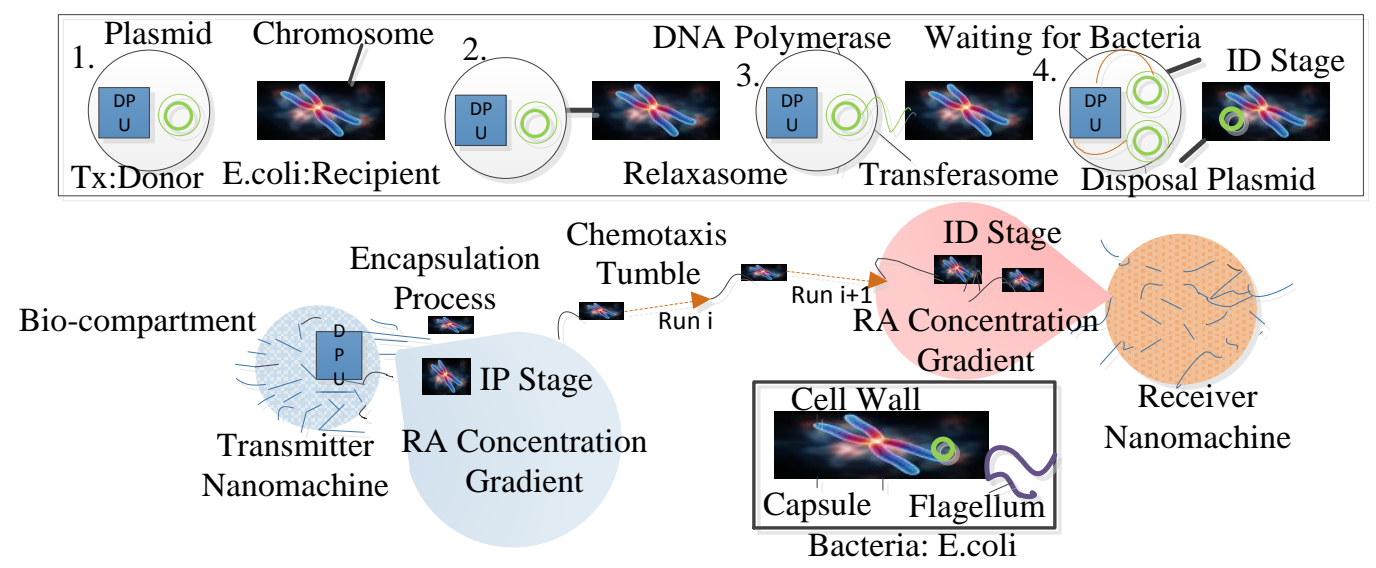

Figure 16. Communication stages of molecular communication using bacteria relay.

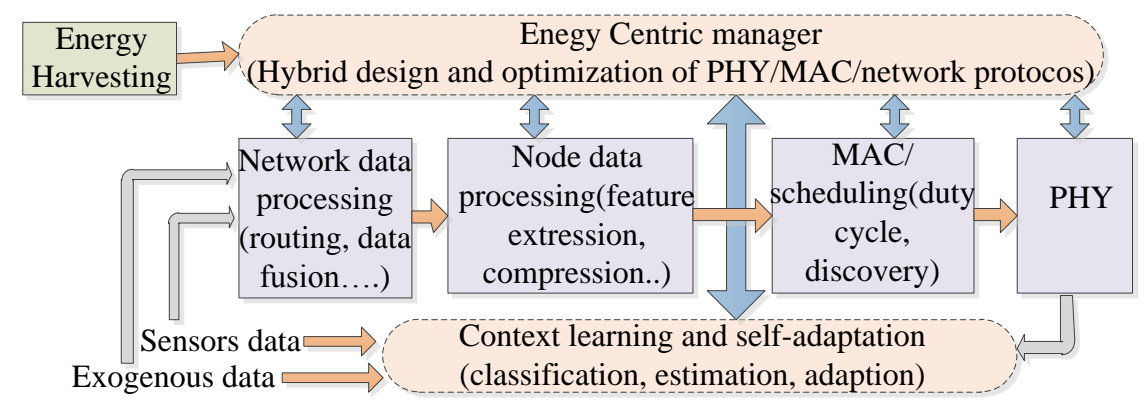

Figure 17. Energy and context centric framework.

Co-locating services in IoT systems to minimize the communication energy cost [51] minimizes computation and communication energy by enabling a service merging technique utilized in mapping and co-located multiple services on devices in IoT applications. After formulating the service co-location problem as a quadratic programming problem, it is reduced to an integer programming problem using a reduction technique in multi hop networks, and modeled as a maximum weighted independent set problem in a single hop network. Using integer programming reduction, the energy cost of a component $C^{i}$ is expressed as:

$$
\delta\left(C^{i}\right)=\sum_{x} \delta_{T}\left(L^{i x}\right)+\sum_{y} \delta_{R}\left(L^{y i}\right)
$$

where $\delta_{T}\left(L^{i x}\right)$ and $\delta_{R}\left(L^{y i}\right)$ are transmission cost of its out-links $L^{i x}$ and receiving cost of its in-links $L^{y i}$ in FBP respectively. Here $p^{i j}=1$ if $C^{i}$ has chosen to be run on device $D^{j}$ then the energy consumption of a device is formulated as:

$$
\delta\left(D^{j}\right)=\sum_{i} p^{i j} * \delta\left(C^{i}\right)
$$

A summary of related literatures on energy efficient communication techniques is given in Tables 12 and 13, which comprises characteristics/protocol, issues, contributions, techniques, simulation tools used, metrics and research limitations of each paper reviewed. 
Table 12. Summary of energy efficient communication techniques.

\begin{tabular}{|c|c|c|c|c|c|c|}
\hline $\begin{array}{ll}\text { Protocols } & \text { Characteristics } \\
\end{array}$ & Issues & Contributions & Techniques & Simulators & Metrics & Limitations \\
\hline FFSC & $\begin{array}{l}\text { Maintain tradeoff between } \\
\text { energy efficiency and delay }\end{array}$ & $\begin{array}{l}\text { Energy efficient solution } \\
\text { with minimized delay }\end{array}$ & $\begin{array}{l}\text { Fast data collection for node } \\
\text { Farthest away from the sink and } \\
\text { Slow data collection for node } \\
\text { Closest to the Sink technique, }\end{array}$ & OMNET++ & $\begin{array}{l}-\mathrm{EE} \\
-\mathrm{DL} \\
-\mathrm{NL}\end{array}$ & $\begin{array}{l}\text { Link quality has not been } \\
\text { considered }\end{array}$ \\
\hline $\mathrm{MCvB}$ & $\begin{array}{l}\text { Low capacity, more delay } \\
\text { and sensitivity to } \\
\text { environmental parameters } \\
\text { via deffusion }\end{array}$ & $\begin{array}{l}\text { Superior energy efficiency } \\
\text { for long distance and } \\
\text { delay sensitive } \\
\text { communication }\end{array}$ & Bacteria mobile relay technique & - & $\begin{array}{l}-\mathrm{EE} \\
-\mathrm{NDIB} \\
-\mathrm{DR}\end{array}$ & $\begin{array}{l}\text { Inferior Energy efficiency in } \\
\text { short distance and delay } \\
\text { tolerant communication. }\end{array}$ \\
\hline EC-CENTRIC & $\begin{array}{l}\text { Ill design network, } \\
\text { processing and resource } \\
\text { management solution }\end{array}$ & $\begin{array}{l}\text { Energy efficiency in } \\
\text { dynamic environment }\end{array}$ & $\begin{array}{l}\text { Energy centric and context aware } \\
\text { optimization technique }\end{array}$ & - & $\begin{array}{l}-\mathrm{NL} \\
-\mathrm{ND} \\
-\mathrm{QoS}\end{array}$ & $\begin{array}{l}\text { Functionalities such as } \\
\text { Energy harvesting, wakeup } \\
\text { radios and protocol } \\
\text { adaptation have not been } \\
\text { considered }\end{array}$ \\
\hline FBP & Communication energy cost & $\begin{array}{l}\text { Less computation time } \\
\text { and energy cost }\end{array}$ & $\begin{array}{l}\text { Maximum weight independent } \\
\text { set approach based on clustering }\end{array}$ & - & $\begin{array}{l}\text {-T-Ratio } \\
\text {-L-Ratio }\end{array}$ & $\begin{array}{l}\text { Vital parameters such as } \\
\text { Delay, link quality have not } \\
\text { been considered. }\end{array}$ \\
\hline
\end{tabular}

Table 13. Comparative assessment of energy efficient communication techniques.

\begin{tabular}{|c|c|c|c|c|c|c|c|c|c|c|c|c|c|c|}
\hline \multirow{2}{*}{ Protocol/Author } & \multicolumn{5}{|c|}{ Approaches } & \multicolumn{9}{|c|}{ Metrics } \\
\hline & MAC & BMR & DC & CA & CLT & DL & EE & T-Ratio & L-Ratio & NL & ND & NDIB & DR & QoS \\
\hline $\begin{array}{c}\text { FFSC [48] } \\
\text { MCvB [49] } \\
\text { EC-CENTRIC [50] } \\
\text { FBP [51] }\end{array}$ & $\begin{array}{l}\sqrt{ } \\
\sqrt{ }\end{array}$ & $\sqrt{ }$ & $\begin{array}{l}\sqrt{ } \\
\sqrt{ }\end{array}$ & $\sqrt{ }$ & $\begin{array}{l}\sqrt{ } \\
\sqrt{ }\end{array}$ & $\sqrt{ }$ & $\begin{array}{l}\sqrt{ } \\
\sqrt{ } \\
\sqrt{ } \\
\sqrt{ }\end{array}$ & $\sqrt{ }$ & $\sqrt{ }$ & $\begin{array}{l}\sqrt{ } \\
\sqrt{ }\end{array}$ & $\sqrt{ }$ & $\sqrt{ }$ & $\sqrt{ }$ & $\sqrt{ }$ \\
\hline
\end{tabular}


In Table 13, the characteristics of each paper reviewed are categorized into three including protocol/author, approach, and metrics. The protocol/author column comprises abbreviations of techniques and references. The approach column is categorized into five classes, namely, MAC, BMR, DC, CA and CLT. The last column represents metrics including DL, EE, T-ratio, L-ratio, NL, ND, NDIB, DR and QoS. Considering Table 13, the approaches in columns two, three and five demonstrate that more contributions have been made by MAC-, DC- and CLT-based techniques, followed by BMR, and CA techniques. Further, the metrics column shows that EE is the most considered metric for measuring the performance of energy efficient communication techniques, followed by NL, then DL, ND and DR.

\subsection{Energy Efficient Cloud Computing Techniques}

In this section, energy efficient techniques at the cloud processing and storage layer have been described in two categories, namely energy efficient virtual machine optimization and Lyapunov optimization techniques.

\subsubsection{Energy Efficient Virtual Machine Optimization Techniques}

An evergreen cloud: Optimizing energy efficiency in heterogeneous cloud computing architectures [52,53] has been introduced for solving energy efficiency problem using novel mathematical optimization model based on VM migration in cloud data center under IoT applications. Moreover a robust energy efficiency scheduling procedure, not dependent on live migration is offered. This whole technique is termed Smart VM Over Provision (SVOP) (Figure 18).

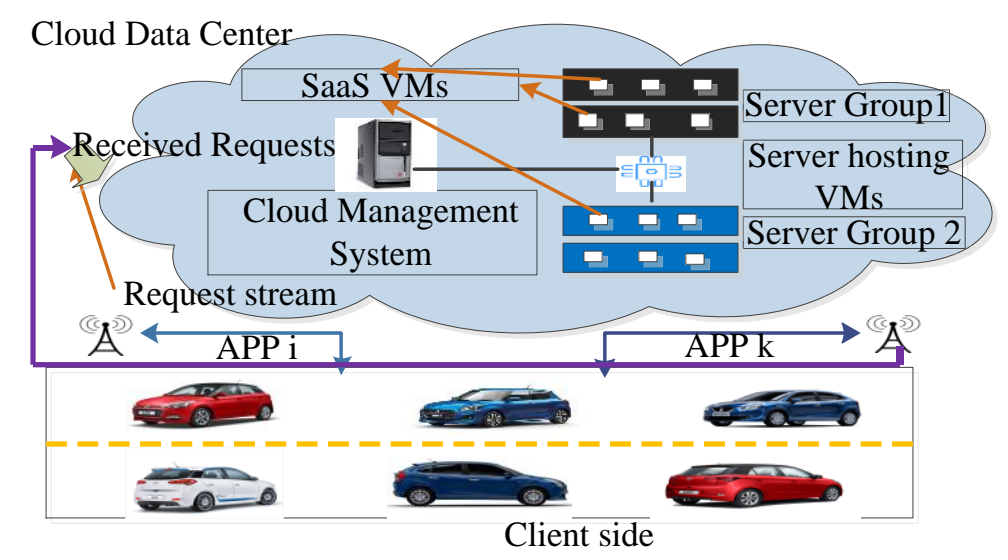

Figure 18. Heterogeneous IoT client sending various requests to a public cloud.

Predictive Optimization-based Energy efficiency for cloud computing system (POEE) [54] has been proposed to optimize energy consumption and maintain system performance, firstly by predicting the resource usage of upcoming period using a Gaussian process regression approach for resource orchestration in cloud computing-based IoT. An appropriate numbers of physical servers are computed using a convex optimization technique for every monitoring window. Finally, the objective of energy saving is achieved by issuing a corresponding migration instruction to stack the virtual machine and turn off the idle physical servers. The Lagrangian function of optimization problem is formulated as:

$$
F\left(a^{k}, \beta\right)=\gamma^{k} s^{n}\left(l^{k}\left(\frac{\vartheta^{k}}{a^{k}}\right)-l\right)+s^{k} a^{k} P^{i d l e}+\beta\left(a^{k}-\frac{\vartheta^{k}}{l^{k(-1)}(l)}\right)+\omega\left(0-a^{k}\right)
$$

where $s^{k} a^{k} P^{i d l e}$ is the energy cost of the running machine. This technique is not well suited for real life scenarios. 


\subsubsection{Energy Efficient Lyapunov Optimization Techniques}

Dynamic Resource and Task Allocation for Energy Minimization in Mobile Cloud Systems (DREAM) [52] has been proposed by invoking Lyapunov optimization to solve jointly three dynamic problems: first, determining the use of local CPU or cloud resources, second, task allocation to transmit across the network and processing in local CPU and third, CPU clock speed and network interface controls. DREAM minimizes the energy usage of mobile nodes while considering delay constraints under heavy traffic in an IoT cloud system. Lyapunov drift plus penalty function is defined as sum of expected network and CPU energy consumption during time slot s, and formulated as:

$$
\Delta(L(s))+V E\left\{E^{c}\left(r^{c}(s)\right)+E^{n}(l(s)) \mid Q(s)\right\}
$$

where $V$ is energy-delay trade off parameter.

Summaries of the related literatures on energy efficient cloud computing techniques are given in Tables 14 and 15, which comprise characteristics/protocol, issues, contributions, techniques, simulation tools used, metrics and research limitations of each paper reviewed.

In Table 15, the characteristics of each paper reviewed are categorized into three groups, including protocol/author, approach, and metrics. The protocol/author column comprises abbreviations of techniques and references. The approach column is categorized into five classes, namely, SVM, LO, PO, QoS and CLT. Last column represents metrics including DL, EE, PD, EUS, AR, PC, CU and NoM. Considering Table 15, the approaches in column four demonstrate that more contributions have been made by QoS-based techniques, followed by SVM, LO, PO and CLT techniques. Further, the metrics column shows that EE is the most considered metric, followed by DL and CU then PD, EUS and AR for measuring performance of energy efficient cloud computing techniques. 
Table 14. Summary of energy efficient cloud computing techniques.

\begin{tabular}{|c|c|c|c|c|c|c|}
\hline $\begin{array}{ll}\text { Protocols } & \text { Characteristics } \\
\end{array}$ & Issues & Contributions & Techniques & Simulators & Metrics & Limitations \\
\hline DREAM & $\begin{array}{l}\text { Increasing cpu and energy } \\
\text { consumption in mobile device }\end{array}$ & $\begin{array}{l}\text { Energy efficient and } \\
\text { fairly scheduled } \\
\text { solution with less delay }\end{array}$ & $\begin{array}{l}\text { Lyapunov optimization } \\
\text { technique }\end{array}$ & $\begin{array}{l}\text { Android phone } \\
\text { (Galaxy note2) }\end{array}$ & $\begin{array}{l}-\mathrm{DL} \\
-\mathrm{EE} \\
-\mathrm{PD}\end{array}$ & $\begin{array}{l}\text { Recorded video streaming } \\
\text { has not been evaluated }\end{array}$ \\
\hline SVOP & $\begin{array}{l}\text { High cloud provider cost and } \\
\text { energy consumption }\end{array}$ & $\begin{array}{l}\text { Consolidation based } \\
\text { energy efficient and } \\
\text { robust solution }\end{array}$ & $\begin{array}{l}\text { Smart virtual machine } \\
\text { over provision technique }\end{array}$ & VanetMobiSim & $\begin{array}{l}\text {-EUS } \\
\text {-AR } \\
\text {-NoM }\end{array}$ & Less acceptation rate \\
\hline POEE & $\begin{array}{l}\text { Challenge to balance system } \\
\text { performance and power } \\
\text { consumption }\end{array}$ & $\begin{array}{l}\text { Energy efficient and } \\
\text { adaptive solution }\end{array}$ & $\begin{array}{l}\text { Predictive and convex } \\
\text { optimization technique }\end{array}$ & $\begin{array}{l}\text { NS-2 and SUMO } \\
\text { EvalVid }\end{array}$ & $\begin{array}{l}-\mathrm{PC} \\
-\mathrm{DL} \\
-\mathrm{CU}\end{array}$ & $\begin{array}{l}\text { Limited to homogenous } \\
\text { environment and not } \\
\text { suitable in real life } \\
\text { scenarios }\end{array}$ \\
\hline
\end{tabular}

Table 15. Comparative assessment of energy efficient cloud computing techniques.

\begin{tabular}{|c|c|c|c|c|c|c|c|c|c|c|c|c|c|}
\hline \multirow{2}{*}{ Protocol/Author } & \multicolumn{5}{|c|}{ Approaches } & \multicolumn{8}{|c|}{ Metrics } \\
\hline & SVM & LO & PO & QoS & CLT & DL & $\mathrm{EE}$ & PD & EUS & AR & PC & $\mathrm{CU}$ & NoM \\
\hline $\begin{array}{c}\text { DREAM [52] } \\
\text { SVOP [53] } \\
\text { POEE [54] }\end{array}$ & $\sqrt{ }$ & $\sqrt{ }$ & $\sqrt{ }$ & $\begin{array}{l}\sqrt{ } \\
\sqrt{ }\end{array}$ & $\sqrt{ }$ & $\begin{array}{l}\sqrt{ } \\
\sqrt{ }\end{array}$ & $\begin{array}{l}\sqrt{ } \\
\sqrt{ } \\
\sqrt{ }\end{array}$ & $\sqrt{ }$ & $\sqrt{ }$ & $\sqrt{ }$ & $\sqrt{ }$ & $\begin{array}{l}\sqrt{ } \\
\sqrt{ }\end{array}$ & $\sqrt{ }$ \\
\hline
\end{tabular}




\subsection{Energy Efficient Techniques at the Application Layer}

A green and reliable communication modeling for industrial internet of things [55], named Hybrid Transmission Protocol (HTP) is a combination of a send-wait automatic repeat request approach in hotspot areas and a network coding-based redundant transmission approach in non-hotspot areas for industrial IoT applications. HTP has been proposed to maximize lifetime, to save energy and to minimize delays in the network. If $E^{\text {in }}$ is initial energy of node, $d$ is data size and $k$ is maximum time for retransmission under send-wait automatic repeat request approach. Then lifetime of whole network under HTP technique is expressed as:

$$
L=\left\{\begin{array}{cl}
\frac{E^{i n}}{k d E^{e l e}+k(d+1) E^{e l e}+k(d+1) \epsilon_{f s} d^{2}}, & \text { if } l<l_{0} \\
\frac{E^{i n}}{k d E^{e l e}+k(d+1) E^{l e}+k(d+1) \epsilon_{a m p} d^{4}}, & \text { if } l>l_{0}
\end{array}\right.
$$

and end to end reliability can be formulated as:

$$
R^{e 2 e}=\prod_{i=1}^{n+1}\left(1-(1-R)^{k_{i}} \prod_{i=n+2}^{N} \sqrt{1-R_{l}^{h_{i}+2}-\left(h_{i}+2\right) R_{l}^{h_{i}+1}\left(1-R_{l}\right)}\right)
$$

where $k_{i}$ is maximum time for retransmission under send-wait automatic repeat request approach for node $i$ and $h_{i}$ is redundancy level of node $i$ under network coding based redundant transmission approach. Energy-Efficient Dynamic Packet Downloading for Medical IoT Platforms (EEDPD) [56] utilizes dynamic energy efficient technique to compute amount of power allocated in every access point which is based on channel state and buffer backlog size considering buffer stability to enhance power/energy management.

The medical cloud computing architecture (Figure 19) consists of various key element: medical users (mobile phone, tablet etc.), access points and medical cloud.

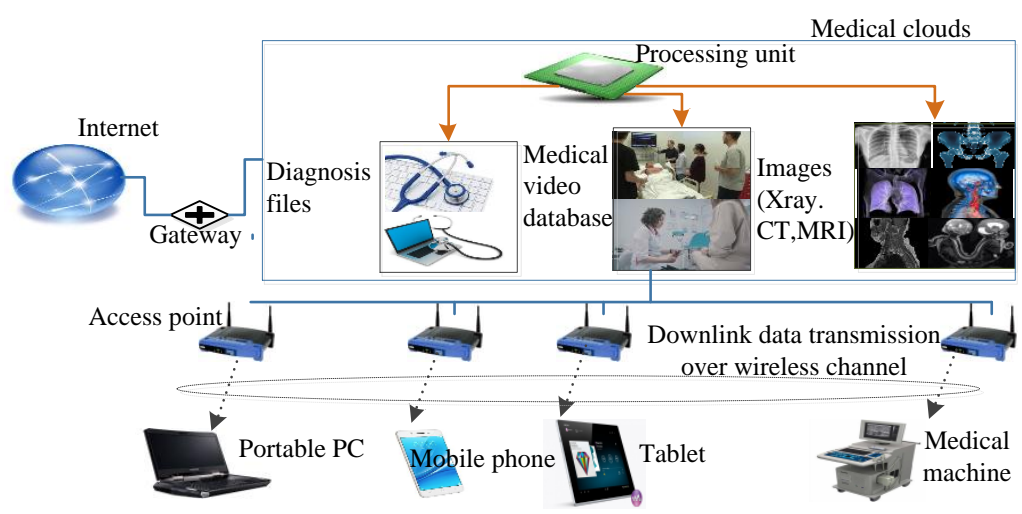

Figure 19. Medical cloud computing system architecture.

The medical cloud containing its own processing unit, can generate relational maps and find meaningful patient information while performing data mining process. Related medical information is downloaded by medical users from central medical cloud platforms. In this technique quality-ware operations are not considered in medical imagining cloud networks. Optimized Day-Ahead Pricing with Renewable Energy Demand-Side Management for Smart Grids (ODAP) [57] has been suggested while considering renewable energy buying-back technique with dynamic pricing to make energy efficient system for smart grid enabled IoT. In this technique, a day-ahead time-dependent pricing scheme has been proposed distributively to enhance user privacy, after formulating dynamic pricing problem as a convex optimization dual problem for providing benefit to both user and electric 
companies. According to Figure 20, a power delivery system is composition of an electric company and users having energy storage devices, and renewable energy generation devices (wind turbine).

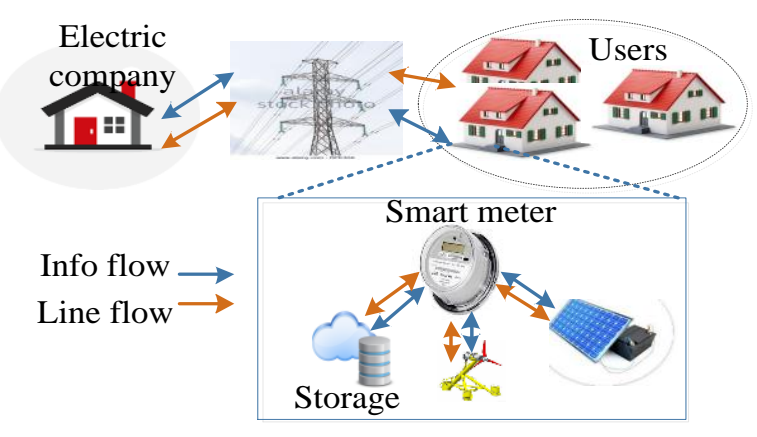

Figure 20. Power delivery system overview.

From the user's perspective, if $l_{k}$ is electricity consumed by each user with charged/discharged rate $r_{k}$ and $m_{k}$ is renewable energy sold by each user in time slot $k$, then welfare of every user is formulated as:

$$
W\left(l_{k}^{i}, n_{k}^{i}\right)=\sum_{k}^{K}\left(U\left(l_{k}^{i}, n_{k}^{i}\right)-R_{s}\left(r_{k}^{i}\right)-R_{r}\left(m_{k}^{i}\right)-P_{k} \times\left(l_{k}^{i}+r_{k}^{i}\right)+E_{k} \times m_{k}^{i}\right)
$$

where $U\left(l_{k}^{i}, n_{k}^{i}\right)$ is the utility function of user, $R_{s}\left(r_{k}^{i}\right)+R_{r}\left(m_{k}^{i}\right)+P_{k} \times\left(l_{k}^{i}+r_{k}^{i}\right)$ is the total cost of every user and $E_{k} \times m_{k}^{i}$ is the profit after selling renewable energy back to grid. A summary of related literatures on energy efficient techniques at the application layer is given in Tables 16 and 17, which comprises characteristics / protocol, issues, contributions, techniques, simulation tools used, metrics and research limitations of each paper reviewed.

In Table 17, characteristics of each paper reviewed are categorized into three groups including protocol/author, approach, and metrics. The protocol/author column comprises abbreviations of techniques and reference. The approach column is categorized into five groups, namely SVM, NCRT, DA, DAP and REBB. Last column represents metrics including DL, EE, GL, GV, LLR, PAR, PDR and NL. Considering Table 17, the approaches in every column contribute equally. Further, the metrics column shows that EE is the most considered metric, followed by NL then PDR, LLR and PAR for measuring performance of energy efficient techniques at the application layer. 
Table 16. Summary of energy efficient techniques at application layer.

\begin{tabular}{|c|c|c|c|c|c|c|}
\hline $\begin{array}{ll}\text { Protocols } & \text { Characteristics } \\
\end{array}$ & Issues & Contributions & Techniques & Simulators & Metrics & Limitations \\
\hline HTP & $\begin{array}{l}\text { Energy consumption, } \\
\text { delay and reliabilty }\end{array}$ & $\begin{array}{l}\text { Green and reliable } \\
\text { communication }\end{array}$ & $\begin{array}{l}\text { send-wait automatic repeat } \\
\text { request and network coding } \\
\text { based redundant } \\
\text { transmission techniques }\end{array}$ & OMNET++ & $\begin{array}{l}\text {-DL } \\
\text {-EC } \\
\text {-NL } \\
\text {-PDR } \\
\text {-LLR }\end{array}$ & $\begin{array}{l}\text { Bad performance in case of } \\
\text { small link loss rate }\end{array}$ \\
\hline EEDPD & $\begin{array}{l}\text { Problem of buffer } \\
\text { stabilization and } \\
\text { energy efficiency }\end{array}$ & $\begin{array}{l}\text { Reliable, robust } \\
\text { and energy } \\
\text { efficient solution }\end{array}$ & $\begin{array}{l}\text { Energy efficient dynamic } \\
\text { allocation technique }\end{array}$ & NS-2 & $\begin{array}{l}-\mathrm{EE} \\
-\mathrm{NL}\end{array}$ & $\begin{array}{l}\text { Quality awareness has not } \\
\text { been considered. }\end{array}$ \\
\hline
\end{tabular}

Table 17. Comparative assessment of energy efficient techniques at application layer.

\begin{tabular}{|c|c|c|c|c|c|c|c|c|c|c|c|c|c|}
\hline \multirow{2}{*}{ Protocol/Author } & \multicolumn{5}{|c|}{ Approaches } & \multicolumn{8}{|c|}{ Metrics } \\
\hline & SW-ARQ & NCRT & DA & DAP & REBB & DL & EE & GL & GV & LLR & PAR & PDR & NL \\
\hline $\begin{array}{c}\text { HTP [55] } \\
\text { EEDPD [56] } \\
\text { OPAD [57] }\end{array}$ & $\sqrt{ }$ & $\sqrt{ }$ & $\sqrt{ }$ & $\sqrt{ }$ & $\sqrt{ }$ & $\sqrt{ }$ & $\begin{array}{l}\sqrt{ } \\
\sqrt{ } \\
\sqrt{ }\end{array}$ & $\sqrt{ }$ & $\sqrt{ }$ & $\sqrt{ }$ & $\sqrt{ }$ & $\sqrt{ }$ & $\begin{array}{l}\sqrt{ } \\
\sqrt{ }\end{array}$ \\
\hline
\end{tabular}




\section{Open Research Issues in Energy Oriented IoT}

Many issues related to energy consumption have been solved and isolated by researchers, but still there are challenges to solve existing issues. An insight is provided related to existing issues faced to attain in energy efficient system. The research issues that require attention are as follows:

- Cross layer interoperability

Several algorithms and techniques working separately on a particular layer of IoT architecture are introduced for energy efficiency in the IoT. Combining them in single operational solution is an existing challenge. The concept of interoperability should be stabilized and privileged by the system to avoid oscillation among layers [34]. Moreover, there should be enough flexibility in the system, while changing a certain techniques such as energy efficiency of a particular layer without affecting the whole IoT system. Figure 21 represents the concept of interoperability of IoT layers: sensing, local processing and storage, network, cloud processing and storage, and application, in terms of various techniques related to energy efficiency, mobility, and security and QoS parameters. This cross layer interoperability makes a IoT system more effective and efficient in various IoT applications [58-65].

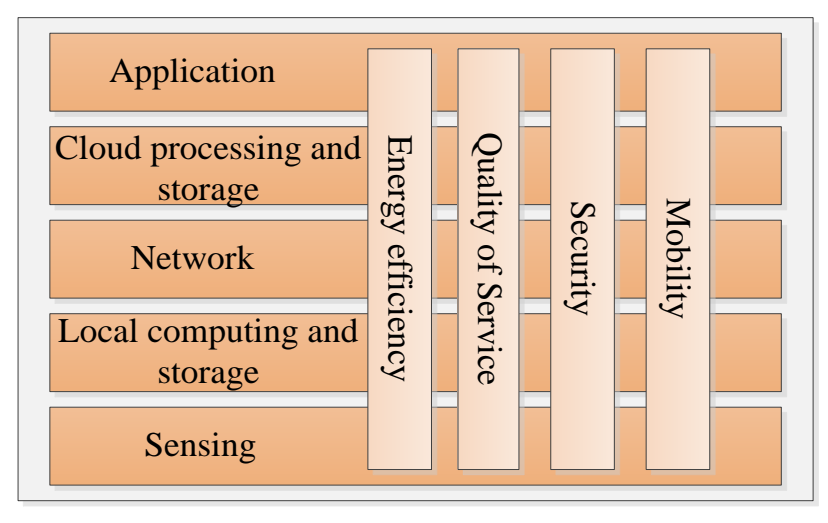

Figure 21. Cross layer interoperability.

- Energy is omnipresent Potential of energy harvesting

In the form of light, temperature, motion, wind, electric, sound, mechanical etc., but only needs to be harvested. Cyber-physical systems, which are a new area in IoT, combine networking and computing with physical processes [36]. These processes can be human controlled or autonomous. IoT-based smart sensors gather, control and measure the information and communicate to the base station [37]. Because of the battery limitations of the devices, energy harvesting is necessary, using natural energy resources like wind, vibration power, solar and thermal power [39]. Due to unreachability of these devices in many cases, energy efficiency to support these devices through energy harvesting techniques is an important research issue. In Figure 22, various natural energy resources those can be potentially utilized for energy harvesting are illustrated. The usage of energy resources such as solar power, vibration power, thermal power, wireless power and wind power may solve the issue of battery limitation in terms of energy through various energy harvesting techniques, in the IoT environment [62]. 


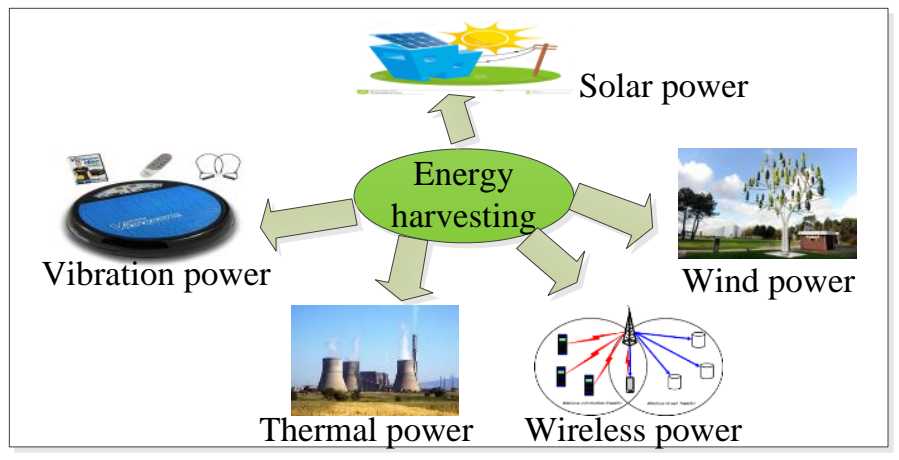

Figure 22. Energy harvesting in IoT.

\section{- Interactivity limitations}

A network can be created for processing and managing data on various remote servers joined together rather than by a local computer or server in the cloud computing environment [52]. The cloud provides sharable resources among multiple users, while making accessible large amounts of information gathered from IoT devices for analysis and processing [53]. In the case of gathering large amount of data from devices it creates multiple effects such as more energy consumption [54]. As a result new approaches and research can be introduced for reducing the device interactivity to minimize energy consumption in IoT applications [63-66]. In Figure 23, location-based interaction based on the cloud and IoT is illustrated. Location-based interactions between IoT devices and users based on cloud computing are one of the effective approaches to overcome the issue of interactivity for making energy efficient IoT system [67].



Figure 23. Location-based IoT and cloud interaction.

\section{- QoS constraints approaches}

Devices have become autonomous and intelligent, because of the usage of new computational concepts like artificial intelligence for the effective deployment of IoT networks [40]. The limitations of energy consumption should be adapted through the association of artificial neural networks. Moreover the QoS constrained system may be controlled in an intelligent manner for every IoT application that may have a distinct energy profile [42]. According to the requirements of every application in an IoT network, novel techniques and research based on QoS constraints can contribute to providing potential solutions [3]. Figure 24 represents a QoS-constrained IoT system, while fulfilling various requirements such as artificial intelligence, to solve the open challenge of energy consumption in IoT applications. 


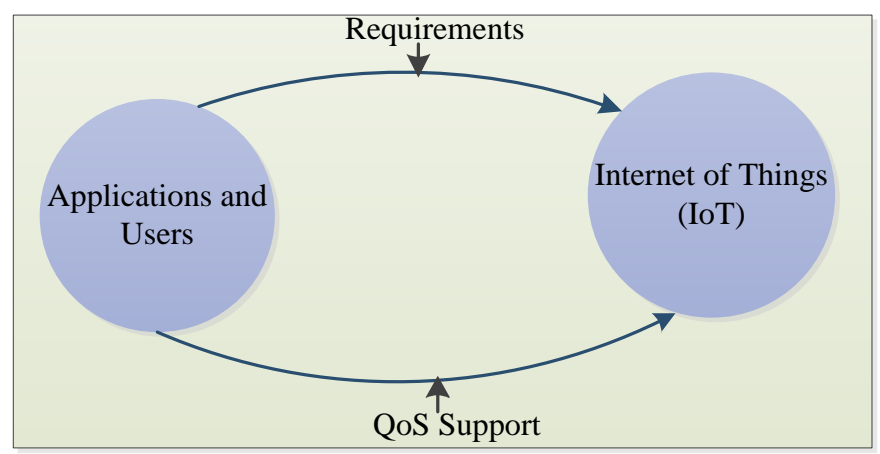

Figure 24. QoS support for IoT.

\section{- Energy efficiency in real time emergency response}

Energy is susceptible to security attacks due to encryption incapability. IoT devices have an energy state within a network, that can be forged, which is called an energy forgery attack. Therefore, energy state privacy preservation issues require attention [58]. Also, some backup can be available for information, but no backup is available for energy. Therefore, this area is one of the research challenges in IoT. Real time performance is one of the most challenging issues in various IoT applications such as medical monitoring, forest fire monitoring and warning and intelligent transportation systems [47]. Improving the real time performance in terms of ensuring emergency response ability, energy efficiency, reliability of data gathering or transmission have become challenging research issues [64]. Through the ERGID technique, an attempt has been made to solve the problem of energy consumption in small-scale emergency response IoT, but the issue of energy efficiency with reliability in large-scale emergency response IoT has become an open research challenge facing researchers [68]. Figure 25 illustrates the real time emergency response in an intelligent transport system, while focusing on the issue of real time performance enhancement using route planning and energy management.

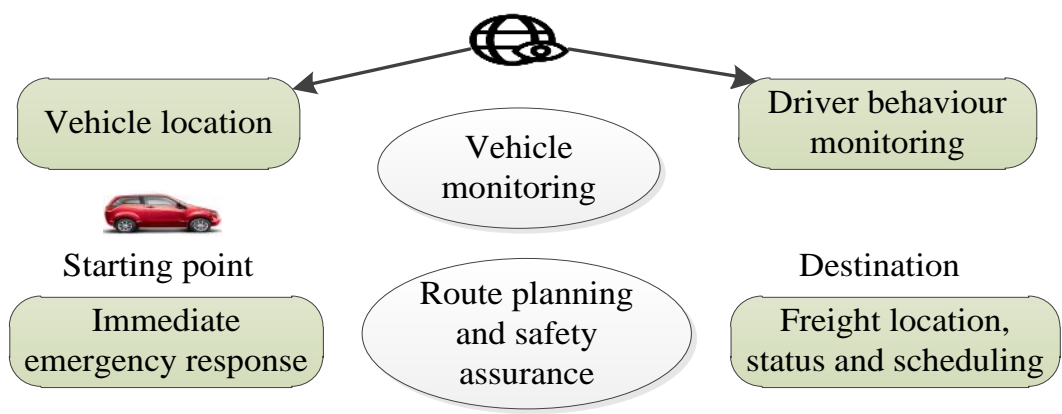

Figure 25. Real time emergency response in intelligent transport system.

\section{- Backhauling in ultra-dense networks}

Powering and backhauling in ultra-dense networks (UDNs) is a critical deployment issue [58]. The main problem in the ultra-dense deployment is taking care of the power requirements of each small cell base station [66]. Because of concern about this problem, the concept of self-backhauling has become an open research field in ultra-dense network-related IoT [69].

\section{Conclusions}

IoT systems are evolving and becoming more common day by day. The energy consumption is the only restriction that constrains the processing of IoT network functionalities. In this study, a comprehensive classification structure and a qualitatively analysis of related publications on energy 
efficient techniques in relation to an IoT perspective have been presented. Different issues and techniques employed in energy efficient techniques in IoT have been analyzed. We have also elaborated future research directions. This review work will improve the understanding of energy efficiency research trends and directions in the IoT, thus hopefully stimulating research work in the energy-related domain in the IoT by making research gaps finding easier, while better energy-efficient techniques will improve the sensing, computation and communication efficiency in various IoT applications.

Author Contributions: K.K. and O.K. conceived, designed and performed the experiments. K.K. has carried out review with the guidance of O.K. and S.K. The paper is written and revised by K.K. and O.K. The paper is read, and quality improvement suggested by Y.C., J.L., and N.A.

Conflicts of Interest: The authors declare no conflict of interest.

\section{References}

1. Zanella, A.; Bui, N.; Castellani, A.; Vangelista, L.; Zorzi, M. Internet of things for smart cities. IEEE Internet Things J. 2014, 1, 22-32. [CrossRef]

2. Kamalinejad, P.; Mahapatra, C.; Sheng, Z.; Mirabbasi, S.; Leung, V.C.M.; Guan, Y.L. Wireless energy harvesting for the Internet of things. IEEE Commun. Mag. 2015, 53, 102-108. [CrossRef]

3. Kaiwartya, O.; Abdullah, A.H.; Cao, Y.; Prasad, A.M.; Lin, C.; Liu, X. Internet of Vehicles: Motivation, Layered Architecture, Network Model, Challenges and Future Aspects. IEEE Access 2016, 4, 5356-5373. [CrossRef]

4. Grieco, L.A.; Rizzo, A.; Colucci, S.; Sicari, S.; Piro, G.; Paola, D.D.; Boggia, G. IoT-aided robotics applications: Technological implications, target domains and open issues. Comput. Commun. 2014, 54, 32-47. [CrossRef]

5. Aijaz, A.; Aghvami, A.H. Cognitive Machine-to-Machine Communications for Internet-of-Things: A Protocol Stack Perspective. IEEE Internet Things J. 2015, 2, 103-112. [CrossRef]

6. Lin, Y.B. EasyConnect: A Management System for IoT Devices and Its Applications for Interactive Design and Art. IEEE Internet Things J. 2015, 2, 551-561. [CrossRef]

7. Bello, O.; Zeadally, S. Intelligent Device Communication in the Internet of Things. Syst. J. IEEE 2014, 10, 1172-1182. [CrossRef]

8. Evans, D. The Internet of Things: How the Next Evolution of the Internet is Changing Everything; Cisco IBSG: San Francisco, CA, USA, 2011.

9. Atzori, L.; Iera, A.; Morabito, G. The Internet of Things: A Survey. Comput. Netw. 2010, 54, $2787-2805$. [CrossRef]

10. Kaur, N.; Sood, S.K. An Energy-Efficient Architecture for the Internet of Things (IoT). IEEE Syst. J. 2017, 11, 796-805. [CrossRef]

11. Erol-Kantarci, M.; Mouftah, H.T. Energy-efficient information and communication infrastructures in the smart grid: A survey on interactions and open Issues. IEEE Commun. Surv. Tutor. 2015, 17, 179-197. [CrossRef]

12. Machine-to-Machine Communications (M2M). M2M Service Requirements. Available online: http:/ / www.etsi. org/deliver/etsi_ts/102600_102699/102689/01.01.01_60/ts_102689v010101p.pdf (accessed on 14 August 2017).

13. Khan, M.; Silva, B.N.; Han, K. Internet of Things Based Energy Aware Smart Home Control System. IEEE Access 2016, 4, 7556-7566. [CrossRef]

14. Huang, S.C.; Chen, B.H.; Chou, S.K.; Hwang, J.N.; Lee, K.H. Smart Car [Application Notes]. IEEE Comput. Intell. Mag. 2016, 11, 46-58. [CrossRef]

15. Kant, K.; Pal, A. Internet of Perishable Logistics. IEEE Internet Comput. 2017, 21, 22-31. [CrossRef]

16. Roopaei, M.; Rad, P.; Choo, K.K.R. Cloud of Things in Smart Agriculture: Intelligent Irrigation Monitoring by Thermal Imaging. IEEE Cloud Comput. 2017, 4, 10-15. [CrossRef]

17. Tröster, G. Smart Clothes-The Unfulfilled Pledge? IEEE Pervasive Comput. 2011, 10, 87-89. [CrossRef]

18. Al-Fuqaha, A.; Guizani, M.; Mohammadi, M.; Aledhari, M.; Ayyash, M. Internet of Things: A Survey on Enabling Technologies, Protocols, and Applications. IEEE Commun. Surv. Tutor. 2015, 17, 2347-2376. [CrossRef]

19. Lin, J.; Yu, W.; Zhang, N.; Yang, X.; Zhang, H.; Zhao, W. A Survey on Internet of Things: Architecture, Enabling Technologies, Security and Privacy, and Applications. IEEE Internet Things J. 2017, 4, 1125-1142. [CrossRef] 
20. Perera, C.; Liu, C.H.; Jayawardena, S.; Chen, M. A Survey on Internet of Things From Industrial Market Perspective. IEEE Access 2014, 2, 1660-1679. [CrossRef]

21. Kamilaris, A.; Pitsillides, A. Mobile Phone Computing and the Internet of Things: A Survey. IEEE Internet Things J. 2016, 3, 885-898. [CrossRef]

22. Tokognon, C.A.; Gao, B.; Tian, G.Y.; Yan, Y. Structural Health Monitoring Framework Based on Internet of Things: A Survey. IEEE Internet Things J. 2017, 4, 619-635. [CrossRef]

23. Razzaque, M.A.; Jevric, M.M.; Palade, A.; Clarke, S. Middleware for Internet of Things: A Survey. IEEE Internet Things J. 2016, 3, 70-95. [CrossRef]

24. Luong, N.C.; Hoang, D.T.; Wang, P.; Niyato, D.; Kim, D.I.; Han, Z. Data Collection and Wireless Communication in Internet of Things (IoT) Using Economic Analysis and Pricing Models: A Survey. IEEE Commun. Surv. Tutor. 2016, 18, 2546-2590. [CrossRef]

25. Perera, C.; Zaslavsky, A.; Christen, P.; Georgakopoulos, D. Context Aware Computing for The Internet of Things: A Survey. IEEE Commun. Surv. Tutor. 2014, 16, 414-454. [CrossRef]

26. Khan, A.A.; Rehmani, M.H.; A. Rachedi, A. Cognitive-Radio-Based Internet of Things: Applications, Architectures, Spectrum Related Functionalities, and Future Research Directions. IEEE Wirel. Commun. 2017, 24, 17-25. [CrossRef]

27. Ahmed, E.; Yaqoob, I.; Gani, A.; Imran, M.; Guizani, M. Internet-of-things-based smart environments: State of the art, taxonomy, and open research challenges. IEEE Wirel. Commun. 2016, 23, 10-16. [CrossRef]

28. Cao, Y.; Jiang, T.; Han, Z. A Survey of Emerging M2M Systems: Context, Task, and Objective. IEEE Internet Things J. 2016, 3, 1246-1258. [CrossRef]

29. Rajandekar, A.; B. Sikdar, A. Survey of MAC Layer Issues and Protocols for Machine-to-Machine Communications. IEEE Internet Things J. 2015, 2, 175-186. [CrossRef]

30. Botta, A.; Donato, W.; Persico, V.; Pescape, A. Integration of Cloud computing and Internet of Things: A survey. Future Gener. Comput. Syst. 2016, 56, 684-700. [CrossRef]

31. Stojkoska, B.L.R.; Trivodaliev, K.V. A review of Internet of Things for smart home: Challenges and solutions. J. Clean. Prod. 2017, 140, 1454-1464. [CrossRef]

32. Liu, C.H.; Fan, J.; Branch, J.W.; Leung, K.K. Toward QoI and Energy-Efficiency in Internet-of-Things Sensory Environments. IEEE Trans. Emerg. Top. Comput. 2014, 2, 473-487. [CrossRef]

33. Du, R.; Gkatzikis, L.; Fischione, C.; Xiao, M. Energy Efficient Sensor Activation for Water Distribution Networks Based on Compressive Sensing. IEEE J. Sel. Areas Commun. 2015, 33, 2997-3010. [CrossRef]

34. Chen, Y.; Chiotellis, N.; Chuo, L.X.; Pfeiffer, C.; Shi, Y.; Dreslinski, R.G.; Kim, H.S. Energy-Autonomous Wireless Communication for Millimeter-Scale Internet-of-Things Sensor Nodes. IEEE J. Sel. Areas Commun. 2016, 34, 3962-3977. [CrossRef]

35. Akgul, O.U.; Canberk, B. Self-Organized Things (SoT): An energy efficient next generation network management. Comput. Commun. 2016, 74, 52-62. [CrossRef]

36. Ahn, J.H.; Lee, T.J. ALLYS: All You can Send for Energy Harvesting Networks. IEEE Trans. Mob. Comput. 2017. [CrossRef]

37. Mondal, S.; Paily, R. Efficient Solar Power Management System for Self-Powered IoT Node. IEEE Trans. Circuits Syst. I Regul. Pap. 2017, 64, 2359-2369. [CrossRef]

38. Qureshi, F.F.; Iqbal, R.; Asghar, M.N. Energy efficient wireless communication technique based on Cognitive Radio for Internet of Things. J. Netw. Comput. Appl. 2017, 89, 14-25. [CrossRef]

39. Nguyen, T.D.; Khan, J.Y.; Ngo, D.T. Energy harvested roadside IEEE 802.15.4 wireless sensor networks for IoT applications. Ad Hoc Netw. 2017, 56, 109-121. [CrossRef]

40. Khanouche, M.E.; Amirat, Y.; Chibani, A.; Kerkar, M.; Yachir, A. Energy-Centered and QoS-Aware Services Selection for Internet of Things. IEEE Trans. Autom. Sci. Eng. 2016, 13, 1256-1269. [CrossRef]

41. Afzal, B.; Alvi, S.A.; Shah, G.A.; Mahmood, W. Energy efficient context aware traffic scheduling for IoT applications. Ad Hoc Netw. 2017, 62, 101-115. [CrossRef]

42. Song, L.; Chai, K.K.; Chen, Y.; Schormans, J.; Loo, J.; Vinel, A. QoS-Aware Energy-Efficient Cooperative Scheme for Cluster-Based IoT Systems. IEEE Syst. J. 2017, 1447-1455. [CrossRef]

43. Park, S.; Cho, S.; Lee, J. Energy-Efficient Probabilistic Routing Algorithm for Internet of Things. Available online: http:/ / www.ietf.org/rfc/rfc3561.txt (accessed on 14 August 2017). 
44. Machado, K.; Rosário, D.; Cerqueira, E.; Loureiro, A.A.F.; Neto, A.; Desouza, J.N. A Routing Protocol Based on Energy and Link Quality for Internet of Thing Applications. Sensors 2013, 13, 1942-1964. [CrossRef] [PubMed]

45. Chellouge, S. Energy-Efficient Content-Based Routing in Internet of Things. J. Comput. Commun. Sci. Res. 2015, 3, 9-20. [CrossRef]

46. Zhao, M.; Ho, I.W.H.; Chong, P.H.J. An Energy-Efficient Region-Based RPL Routing Protocol for Low-Power and Lossy Networks. IEEE Internet Things J. 2016, 3, 1319-1333. [CrossRef]

47. Qiu, T.; Lv, Y.; Xia, F.; Chen, N.; Wan, J.; Tolba, A. An Efficient Routing Protocol for Emergency Response Internet of Things. J. Netw. Comput. Appl. 2016, 72, 104-112. [CrossRef]

48. Liu, Y.; Liu, A.; Hu, Y.; Li, Z.; Choi, Y.-J.; Sekiya, H.; Li, J. FFSC: An Energy Efficiency Communications Approach for Delay Minimizing in Internet of Things. IEEE Access 2016, 4, 3775-3793. [CrossRef]

49. Qiu, S.; Haselmayr, W.; Li, B.; Zhao, C.; Guo, W. Bacterial Relay for Energy Efficient Molecular Communications. IEEE Trans. Nanobiosci. 2017, 16, 555-562. [CrossRef] [PubMed]

50. Biason, A.; Pielli, C.; Rossi, M.; Zanella, A.; Zordan, D.; Kelly, M.; Zorzi, M. EC-CENTRIC: An Energy- and Context-Centric Perspective on IoT Systems and Protocol Design. IEEE Access 2017, 5, 6894-6908. [CrossRef]

51. Huang, Z.; Lin, K.J.; Yu, S.Y.; Hsu, J.Y. Co-locating services in IoT systems to minimize the communication energy cost. J. Innov. Digit. Ecosyst. 2014, 1, 47-57. [CrossRef]

52. Kwak, J.; Kim, Y.; Lee, J.; Chong, S. DREAM: Dynamic Resource and Task Allocation for Energy Minimization in Mobile Cloud Systems. IEEE J. Sel. Areas Commun. 2015, 33, 2510-2523. [CrossRef]

53. Sharkh, M.A.; Shami, A. An evergreen cloud: Optimizing energy efficiency in heterogeneous cloud computing architectures. Veh. Commun. 2017, 9, 199-210. [CrossRef]

54. Bui, D.M.; Yoon, Y.; Huh, E.N.; Jun, S.; Lee, S. Energy efficiency for cloud computing system based on predictive optimization. J. Parallel Distrib. Comput. 2017, 102, 103-114. [CrossRef]

55. Liu, A.; Zhang, Q.; Li, Z.; Choi, Y.; Li, J.; Komuro, N. A green and reliable communication modeling for industrial internet of things. Comput. Electr. Eng. 2017, 58, 364-381. [CrossRef]

56. Kim, J. Energy-Efficient Dynamic Packet Downloading for Medical IoT Platforms. IEEE Trans. Ind. Inform. 2015, 11, 1653-1659. [CrossRef]

57. Chiu, T.C.; Shih, Y.Y.; Pang, A.C.; Pai, C.W. Optimized Day-Ahead Pricing With Renewable Energy Demand-Side Management for Smart Grids. IEEE Internet Things J. 2017, 4, 374-383. [CrossRef]

58. Gandotra, P.; Jha, R.K.; Jain, S. Green Communication in Next Generation Cellular Networks: A Survey. IEEE Access 2017, 5, 11727-11758. [CrossRef]

59. Wang, K.; Alonso-Zarate, J.; Dohler, M. Energy-efficiency of LTE for small data machine-to-machine communications. In Proceedings of the 2013 IEEE International Conference on Communications (ICC), Budapest, Hungary, 9-13 June 2013.

60. Liu, M.; Crussière, M.; Hélard, J.-F. Improved physical layer for energy-efficient M2M communications over cellular networks. In Proceedings of the 2015 23rd International Conference on Software, Telecommunications and Computer Networks (SoftCOM), Split, Croatia, 16-18 September 2015.

61. Li, J.; Peng, M.; Yu, Y.; Ding, Z. Energy-Efficient Joint Congestion Control and Resource Optimization in Heterogeneous Cloud Radio Access Networks. IEEE Trans. Veh. Technol. 2016, 65, 9873-9887. [CrossRef]

62. Sendra Compte, S.; Lloret, J.; García Pineda, M.; Toledo Alarcón, J.F. Power saving and energy optimization techniques for Wireless Sensor Networks. J. Commun. 2011, 6, 439-459. [CrossRef]

63. Kaiwartya, O.; Abdullah, A.H.; Cao, Y.; Lloret, J.; Kumar, S.; Shah, R.R.; Prasad, M.; Prakash, S. Virtualization in Wireless Sensor Networks: Fault Tolerant Embedding for Internet of Things. IEEE Internet Things J. 2017. [CrossRef]

64. Garcia, M.; Sendra, S.; Lloret, J.; Canovas, A. Saving energy and improving communications using cooperative group-based wireless sensor networks. Telecommun. Syst. 2013, 52, 2489-2502. [CrossRef]

65. Kaiwartya, O.; Abdullah, A.H.; Cao, Y.; Raw, R.S.; Kumar, S.; Lobiyal, D.K.; Isnin, I.F.; Liu, X.; Shah, R.R. T-MQM: Testbed-based multi-metric quality measurement of sensor deployment for precision agriculture-A case study. IEEE Sens. J. 2016, 16, 8649-8664. [CrossRef]

66. Alrajeh, N.A.; Khan, S.; Lloret, J.; Loo, J. Secure routing protocol using cross-layer design and energy harvesting in wireless sensor networks. Int. J. Distrib. Sens. Netw. 2013, 9, 374796. [CrossRef]

67. Li, Y.; Zhou, G.; PenG, G. Energy Modeling and Optimization for BSN and WiFi Networks Using Joint Data Rate Adaptation. Adhoc Sens. Wirel. Netw. 2016, 32, 149-173. 
68. Mehmood, A.; Khan, S.; Shams, B.; Lloret, J. Energy-efficient multi-level and distance-aware clustering mechanism for WSNs. Int. J. Commun. Syst. 2015, 28, 972-989. [CrossRef]

69. Kim, S. Game Based Certificate Revocation Algorithm for Internet of Things Security Problems. Adhoc Sens. Wirel. Netw. 2016, 32, 319-336. 